\title{
Low salinity effects on oil recovery performance: underlying physical mechanisms and practical assessment
}

\author{
B. Bourbiaux* \\ IFP Energies nouvelles, 1 et 4 avenue de Bois-Préau, 92852 Rueil-Malmaison Cedex, France
}

Received: 2 August 2019 / Accepted: 20 April 2020

\begin{abstract}
This paper is a tentative synthesis of the main knowledge and experience gained from recent studies and application of Low Salinity Water Injection (LSWI) in carbonate and clayey silico-clastic rocks. A physical model based on ionic force is presented to explain the so-called Dual Layer Expansion (DLE) mechanism often invoked to account for the Low Salinity Effects (LSE) on rock wettability and oil recovery. The role played by the Multi Ion Exchange (MIE) mechanism is clarified, at least for clayey rocks. Eventually, the proposed physical analysis shows the complementary roles that injected brine concentration and composition can play on waterflood recovery efficiency depending on the Crude Oil Brine Rock (COBR) system under consideration. To account for the diversity of COBR systems, a straightforward modelling methodology is then proposed to simulate laboratory LSWI tests on a case-by-case basis and infer the actual evolution of residual oil saturation with brine concentration and/or composition. The simulation involves a wettability driver that may be either the global salinity or the square root of ionic force. The analysis of published results actually shows that the latter predicts low salinity effects on residual oil saturation better than the former. Hopefully, this paper contributes to the understanding of the DLE and MIE mechanisms induced by a smart water injection and provides a simple and robust methodology to simulate the reference coreflood experiments that remain necessary to assess and optimize LSWI.
\end{abstract}

\begin{tabular}{ll} 
Nomenclature \\
CEC & Cationic Exchange Capacity \\
COBR & Crude Oil Brine Rock \\
DLE & (Ionic) Dual (or Double) Layer Expansion \\
H or HS & High Salinity \\
L or LS & Low Salinity \\
LSE & Low Salinity Effects \\
LSWI & Low Salinity Water Injection \\
MIE & Multi Ion Exchange (or Multi-component Ionic \\
& Exchange) \\
POC & Polar Oil Components \\
SWCTT & Single Well Chemical Tracer Test \\
TDS & Total Dissolved Salts \\
WM & Wettability Modifier \\
$C_{\text {WM }}$ & Concentration of WM \\
$f$ & Interaction force \\
$f_{\text {ow }}$ & Water-oil flow property (Jerauld et al.'s model) \\
$I$ & Ionic force \\
$R_{\text {ads }}$ & Adsorbed amount \\
$S$ & Total ion-mole concentration of the brine \\
& (Appendix) \\
\hline
\end{tabular}

* Corresponding author: bernard.bourbiaux@ifpen.fr

$\begin{array}{ll}S_{\text {orw }} & \text { Residual oil saturation } \\ S_{\text {wi }} & \text { Connate (immobile) water saturation } \\ k_{\text {ro }}\left(k_{\mathrm{rw}}\right) & \text { Relative permeability to oil (water) } \\ P c & \text { Capillary Pressure } \\ V & \text { Physical variable driving wettability change } \\ X & \text { Distance } \\ Z & \text { Ion valence } \\ \alpha, \beta & \text { Solution and adsorbed ion-mole concentration } \\ & \text { ratios (Appendix) } \\ \beta_{G} & \text { Calibration exponent of flow parameter } \\ & G\left(G=S_{\text {orw }}, S_{\text {wi }}, k_{\text {ro }}, k_{\text {rw }}, P c_{\text {ow }}\right) \\ \kappa & \text { Debye-Hückel parameter } \\ v & \text { Molar concentration } \\ \theta & \text { Scaled variation of } S_{\text {orw }} \text { with salinity (Jerauld } \\ \omega & \text { et al.'s model) } \\ \psi & \text { Constant (at given temperature) } \\ & \text { Potential }\end{array}$

\section{Introduction}

The impact of a salinity reduction on oil recovery by water injection was identified for more than two decades by 
Tang and Morrow (1999) from laboratory displacements on clayey sandstones restored in the presence of connate brine and crude oil. A few years later, i.e. 10-15 years ago, the water injection recovery process started to be revisited in depth after a few field observations revealed the benefit of a salinity reduction on oil recovery. The origin of LSE was attributed to a change of rock wettability as revealed from brine to oil spontaneous imbibition tests. Hence, the benefit of a LSWI was soon found to require "customized" water specifically designed for the field rock-fluids system under consideration, and not only a simple salinity reduction of the injected brine.

In the present paper, acknowledged effects of a salinity reduction on oil recovery performance by water injection are reviewed, their physical interpretation is discussed before proposing a numerical model capable to simulate those effects while taking into account experimental artefacts. So, the paper starts with the analysis and discussion of existing studies of LSE, including field evidences of LSE, confirmation by laboratory measurements and investigation of responsible mechanisms of LSE. Although this review is far from exhaustive, main learnings are drawn from reported studies and shed light on the most plausible mechanisms of LSE depending on the rock and fluid compositional characteristics. Then, a generic and easy-toimplement model is proposed to simulate and interpret LSE in brine flooding, either through empirical calibration or taking into account acknowledged physical mechanisms. Procedure and precautions to calibrate the model from laboratory experiments are given in order to reliably assess LSE for subsequent field application.

\section{State of the art}

In the years 2000, some field data and observations led to a growing awareness of the role played by injected brine salinity on water injection performance. These observations have since been the incentive of numerous research studies of possible responsible mechanisms. A tentative review follows, starting with field evidences and going on with laboratory investigation.

\subsection{Field evidence of LSE}

Evidence of Low Salinity Effects (LSE) in reservoir conditions were first highlighted by Webb et al. (2004) and McGuire et al. (2005).

Webb et al. (2004) analysed saturation data from repeated logs (Log-Inject-Log by Pulse Neutron Capture method) run in a well of a Koweit sandstone reservoir after injecting successive brine slugs of decreasing salinity: nearwellbore residual oil saturation was found to decrease by one fourth to half of its value, corresponding to an absolute $S_{\text {orw }}$ decrease of $5-20 \%$ PV with an accuracy of $\pm 5 \%$ PV.

McGuire et al. (2005) gave further evidence of LSE from the interpretation of four Single Well Chemical Tracer Tests (SWCTT) performed in sandstone reservoirs from Alaska's North Slope. $S_{\text {orw }}$ was reduced by $4-9 \%$ PV, and such a decrease was consistent with laboratory displacement tests on cores.

Regarding LSE at reservoir scale, Robertson (2007) analysed the recovery histories of three fairly-clean sandstone reservoirs from Wyoming, cemented by little amounts of carbonates and anhydrite, saturated by a $42-128 \mathrm{~g} / \mathrm{L}$ connate brine and waterflooded by a spring water. Recovery after producing $0,3 \mathrm{PV}$ seems to be correlated to the salinity ratio between injected brine and connate brine for those reservoirs, with a recovery increase in the order of $5 \%$ when salinity is divided by two.

Seccombe et al. (2010) analysed the results of an instructive LSI pilot on Endicott field (Prudhoe Bay, Alaska). A low salinity water injection was performed after a secondary brine injection up to a watercut of $95 \%$. The reservoir rock under consideration was a sandstone with ferrous carbonate cement (siderite) and secondary clays (illitekaolinite). A decrease of watercut from $95 \%$ to $92 \%$ was observed at breakthrough of the low-salinity brine and concomitantly ferrous ions were produced in that low-salinity effluent. Those ions are associated with the partial diagenetic leaching of siderite (involving ferrous ions re-precipitation on quartz and kaolinite). Such ions were suspected to bind polar components of the crude oil to mineral surfaces in native reservoir conditions and the enhanced mobilization of oil was then attributed to an elution of such binding ions. That is, LSE was caused by a modification of rock surface wettability to less oil-wet.

Vledder et al. (2010) also analysed the production of a Syrian oil-wet sandstone field with $0,5-4 \%$ of kaolinite clays and a highly-concentrated connate brine $(90 \mathrm{~g} / \mathrm{L}$ including a high amount of divalent salts). A river water was injected to sustain production. Resistivity open-hole log data and a watercut evolution showing two successive steps were interpreted as evidences of the build-up of an oil bank resulting from oil remobilization by low-salinity water following connate water. Again, that remobilization is assumed to result from a wettability modification by the elution of divalent cations bridging polar oil components and the negatively charged clay mineral surfaces (kaolinite).

Previous observations are given as examples of LSE in sandstone reservoirs. Regarding carbonate reservoirs, a demonstration of LSE from a first field trial is reported by Yousef et al. (2012). SWCTT were performed at two wells involving the successive injections of a seawater followed by the injection of a 10-times diluted seawater in one or two stages (10-times diluted or twice then 10-times diluted). Both tests revealed a decrease by $(7 \pm 1) \% \mathrm{PV}$ of the residual oil saturation in the investigated region extending 3-6 m from wellbore. Such positive results are consistent with extensive laboratory studies from the same authors referred to later on.

However, the benefit of LSE on oil recovery is not systematic as shown by Skrettingland et al. (2010) from core flooding experiments and SWCTT on clayey sandstone formations of the Snorre field. Core flooding tests yielded no or small incremental oil recovery $(0 \%$ or $2 \%$ of the Initial Oil In Place [IOIP]) and SWCTT showed no significant change in $S_{\text {orw }}$. Such results were attributed to close-tooptimal initial wettability conditions in that field. 
In summary, reported field observations show that some of the residual oil trapped by high-salinity or connate brine waterflooding can be remobilized by injecting a brine of reduced salinity. These field evidences of LSE triggered numerous laboratory assessment studies and research to understand the underlying mechanisms and the conditions to be met for a low-salinity water injection to be effective.

\subsection{Coreflood assessment and mechanistic studies of LSE}

Experimental data on cores confirmed the effects observed at field scale. For instance, Jerauld et al. (2008) reported a good consistency between core measurements, logs, and in-situ tests, showing a $S_{\text {orw }}$ reduction ranging from $3 \%$ to $17 \%$ PV. Salinity effects were found to be effective for a salt concentration reduced by a factor in the order of 10 with respect to the connate salinity, with main effects for salinities of $1000-2000 \mathrm{ppm}$.

To interpret waterflooding tests results at different salinities, advanced physico-chemical studies referred to below were undertaken to identify the possible mechanisms responsible for LSE. Those mechanisms, analyzed after in the light of published studies, include:

- The destabilization of clay minerals causing fines migration and modification of flow paths at pore scale.

- An expansion of the ionic layer interacting with the rock and presumably adsorbed oil polar components: that mechanism known as the Double ionic Layer Expansion (DLE) and directly linked to reduced ion concentration (brine dilution effects) concern in particular siliceous and clayey minerals with negative surface charge in native reservoir $\mathrm{pH}$ conditions.

- Multi Ion Exchanges (MIE) between brine and rock minerals concerning mainly initially adsorbed divalent cations, and presumably responsible of modified oilrock interactions.

- An increase of $\mathrm{pH}$ leading to reactions of saponification in the presence of polar oil components.

- Specific ionic interactions involving in particular sulphate ions which are relatively abundant in seawater and suspected to impact the oil recovery from carbonates.

- And also the dissolution or precipitation of mineral phases that may alter the rock surface affinity for oil or brine, and/or pore connectivity.

\subsubsection{Carbonates}

Experimental evidence of brine composition effects on the wettability properties of chalk is found in Webb et al. (2005). They measured the live oil-brine imbibition capillary curves of that rock under reservoir conditions using either a simulated formation brine or a simulated sea water. The entire $P c$ curve, including positive and negative parts, was measured thanks to a specific method, the semidynamic method, developed by Lenormand et al. (1993). The use of sea water containing sulphate anions instead of a more concentrated and sulphate-free formation brine led to a shift of the Pc versus $S_{\mathrm{w}}$ function to the right, meaning that a more water-wet state of the rock is obtained in the presence of sea water than in the presence of connate brine. More precisely, the brine saturation corresponding to zero $P c$ was equal to 0,28 with connate brine, and to 0,38 in the presence of sea water, that is oil recovery by spontaneous imbibition was improved by $10 \%$ PV thanks to the use of sea water.

More recently, a well-documented study on a carbonate reservoir rock-fluid system was performed by Yousef et al. (2011). The acknowledged methodology of LSE assessment consisting in the successive injections of gradually diluted brines was applied to a carbonate field rock-fluid system under reservoir conditions. The injection brine was a sea water $(57,6 \mathrm{~g} / \mathrm{L})$ followed by the same brine composition with Total Dissolved Salts (TDS) reduced by a factor of 2 then 10, 20, and 100. This coreflooding sequence was applied to two cores and led to similar results. The oil recovery was successively increased by $7-8,5 \%$ of the oil in place by twice dilution, by an additional $9-10 \%$ by 10 -times dilution, by $1-2 \%$ by 20 -times dilution, and was not further increased by higher dilution. Complementary measurements of InterFacial Tension (IFT), contact angle and NMR were performed to interpret results. Brine composition and concentration were found to have little effect on IFT values which were ranging between 40 and $32 \mathrm{mN} / \mathrm{m}$. However, contact angle measurements in reservoir conditions showed a gradual decrease from $90^{\circ}$ to $63^{\circ}$ when sea water was diluted by a factor of 2 , then 10 and 20 , and $T 2$ relaxation times measured on cores after low salinity flooding revealed a partial lumping of the two peaks corresponding to macropores and micropores which were separated before the coreflooding sequence. Authors inferred from that observation that low salinity flooding improved the connectivity of micro- and macropores, which could explain the oil recovery increase. Indeed, the studied rock contained anhydrite, a mineral that may be destabilized (dissolved) by external waterflooding at reservoir temperature conditions, thus improving the access to pores and the oil recovery. However, that possible correlation between anhydrite dissolution and oil recovery improvement was not confirmed in another study (Uetani et al., 2019). Still, Zahid et al. (2012) suggest a migration of fines as a possible origin of oil recovery improvement in Middle East carbonate cores. Finally, the well-documented study from Yousef et al. (2011) remains a reference for LSE in carbonates.

Sharifi and Shaikh (2013) correlated the oil recovery increase due to salinity reduction with the value of contact angle and found that the contact angle was a better criterion than salinity level to choose a salinity that optimizes recovery performance. That study performed on outcrop limestone cores also showed that recovery increase occurred mainly when the wettability was changed (i.e., when contact angle dropped from a value $\left(100^{\circ}\right)$ higher than $90^{\circ}$ to a value $\left(73^{\circ}\right.$ ) lower than $90^{\circ}$ ) and not so much more when wettability to aqueous phase was further increased.

The main information drawn from above studies is that LSE can be seen as a wettability alteration process as a 
whole, but without any clear identification of the involved mechanisms which would not involve the brine concentration alone, but also its specific composition as detailed hereafter.

\subsubsection{The role of divalent ions on LSE in carbonates}

Divalent cations and sulphate anions are suspected to play a determinant role in the occurrence of LSE in carbonates. Zhang et al. (2007) performed spontaneous imbibition experiments on an outcrop chalk (Stevns Klint) with different concentrations of divalent cations and of sulphate anions. The improved spontaneous imbibition observed in the presence of such ions was interpreted as a wettability change of the rock according to a catalytic effect of sulphate anions that liberates adsorbed organic acids from positively charged rock surface sites and makes possible their interaction with divalent cations (especially $\mathrm{Mg}^{2+}$ at temperatures above $100{ }^{\circ} \mathrm{C}$ ) in solution. Beside their significant concentration in sea water, sulphate anions may result from the presence of anhydrite in some carbonates which could be subject to dissolution in the injected brine depending on its concentration, composition and the reservoir temperature (Austad et al., 2012). According to Romanuka et al. (2012), the predominant role of sulphates over that of a reduced salinity would be specific to that outcrop chalk (Stevns Klint). However, several recent studies on a dolomitic reservoir (Kasmaei and Rao, 2014) and on rock-fluid systems from UAE carbonate reservoirs (Zhang and Sarma, 2012) showed that both the reduction of salinity and the addition of sulphate anions at reservoir temperature improved the oil recovery and decreased the rock wettability to oil.

More generally, the role of divalent ions, namely $\mathrm{Ca}^{2+}$, $\mathrm{Mg}^{2+}$, and $\mathrm{SO}_{4}^{2-}$, on carbonate rock wettability was investigated by Kwak et al. (2014) from Nuclear Magnetic Resonance (NMR) measurements. They showed that the $T 2$ relaxation time was modified in the presence of those divalent ions as a result of their interaction with carbonate pore walls, with a higher affinity of magnesium and sulphate than of calcium.

Two recent studies of crude oils, brines and carbonates systems including dedicated wettability characterization (Fattahi Mehraban et al., 2019; Zaheri et al., 2020) confirmed the favorable impact of sulphates in the injection brine on the oil recovery, especially at elevated temperatures, and the major contribution of divalent cations to the oil-wet state of the rock with detrimental impact on the oil recovery.

\subsubsection{Sandstones}

The frequent presence of clays often determines LSE mechanisms in siliciclastic reservoirs.

The migration of fines was early identified by Tang and Morrow (1999) as a major reason for the impact of a salinity decrease of the injection brine on the oil recovery. These authors conclude that LSE require the joint presence of a connate brine, of crude oil whose components can adsorb on the rock surface, and of potentially mobile fines.

Later, low salinity corefloods on sandstones reported by McGuire et al. (2005) revealed an increase of $\mathrm{pH}$, which was attributed to rock surface reactions (cation release and adsorption of $\mathrm{H}^{+}$) and considered as the main mechanism of LSE. In the presence of crude oil with acid polar components, that $\mathrm{pH}$ increase would generate natural surfactants whose stability in solution would be ensured by the low content or absence of divalent cations in smart water.

Next, Lager et al. (2008) showed that Multi-component Ionic Exchange (MIE) is a primary mechanism associated with low salinity effects on oil recovery. Their experiment on an Alaska reservoir sandstone with prior elimination of adsorbed divalent cations showed that a high oil recovery could be obtained whatever the salinity level.

Actually, the injection of a low-concentration divalentfree brine induces both an expansion of the layer of cations interacting with the negatively charged clay mineral surface and the replacement of divalent cations by monovalent ones in that layer. These two mechanisms of ionic layer expansion (known as the electrical Double Layer Expansion, referring to adsorbed and diffuse ion layers) and cationic exchange are supported by Lee et al.'s research study (2010). By using the Small Angle Neutron Scattering technique, they showed that the electrical double layer thickness around charged silica particles increases when the brine concentration decreases. Furthermore, that thickening effect is amplified when the divalent cations of the initial brine are replaced by monovalent cations. One may then assume that brine dilution and divalent cation replacement can jointly weaken the cationic bridging of negatively charged polar oil components and mineral surfaces and thus lead to a wettability change of the rock via a detergency mechanism, in favor of an increased oil recovery.

Austad et al. (2010) proposed a chemical model for LSE in clayey sandstones. During a low salinity injection, adsorbed cations, especially divalent cations $\mathrm{Ca}^{2+}$ or $\mathrm{Mg}^{2+}$ ), are no more in equilibrium with the aqueous solution, hence are desorbed and replaced by protons $\mathrm{H}^{+}$ from the aqueous solution, that is:

$$
\text { Clay }-\mathrm{Ca}^{2+}+\mathrm{H}_{2} \mathrm{O} \rightarrow \text { Clay }-\mathrm{H}^{+}+\mathrm{OH}^{-}+\mathrm{Ca}^{2+} .
$$

The liberated hydroxyl anions are associated with a $\mathrm{pH}$ increase and can then react with the acidic or basic polar oil components adsorbed on the clay surface that are responsible for the (partial) oil wetness of the rock:

$$
\begin{gathered}
\text { Clay }-\mathrm{RCOOH}+\mathrm{OH}^{-} \rightarrow \text { Clay }+\mathrm{RCOO}^{-}+\mathrm{H}_{2} \mathrm{O}, \\
\text { Clay }-\mathrm{NHR}_{3}^{+}+\mathrm{OH}^{-} \rightarrow \text { Clay }+\mathrm{R}_{3} \mathrm{~N}+\mathrm{H}_{2} \mathrm{O} .
\end{gathered}
$$

Last reaction above is assumed to take place because the pKa constant of basic oil components is not very different from that of acidic oil components. Both reactions above would alter the wettability of clayey sandstones. The magnitude of such cation exchange mechanisms depends on the nature of clay (mainly kaolinite, illite, chlorite, or montmorillonite, characterized by different alumino-silicate layer structures) and on its cation exchange capacity.

Suijkerbuijk et al. (2012) undertook a systematic laboratory assessment study of LSE on outcrop and reservoir clayey sandstones aged in the presence of brines of various compositions in monovalent and divalent cations, 
and 13 oils characterized by their total acid and base numbers, component categories, etc. Assessment was based on the spontaneous imbibition of aged cores in formation brine then in brines of different compositions and concentrations. That extensive study showed that the brine salt concentration alone is not a sufficient condition to improve the oil recovery significantly. Low salinity effect on recovery is effective if the initial formation brine contains divalent cations, in as much as divalent cations also favor the oil wetness of the rock. Divalent cations are here assumed to act as binding ions between rock surface and polar oil components. Authors conclude that both cation exchange (MIE) and brine dilution (DLE) may be responsible for LSE but that the required sufficient conditions for LSE to work in a field are not yet identified.

\subsubsection{Rock surface electrical charge as a possible indicator of LSE}

The electrical charge of a surface can be assessed from the so-called zeta-potential that is determined from electrokinetic measurements at the shear limit between adsorbed ions and diffuse ions layer. Several studies support the existence of a correlation between zeta-potential measurements and the occurrence of LSE.

In a study on 18 combinations of different crude oils, brines and sandstones, Van Winden et al. (2013) found that the additional recovery associated with a salinity decrease to $2 \mathrm{~g} / \mathrm{L}$ was best correlated with rock zeta potential values, especially when changing of sign with decreasing salinity. This is consistent with a possible repulsion of oil drops having also a negative zeta potential if holding some acid polar oil components.

Alroudhan et al. (2015) realized zeta potential measurements on coarse carbonate rock samples (not crushed) in brines of various concentrations and compositions in divalent cations and sulphate anions. The presence of divalent cations in brine renders the zeta potential of calcite positive whereas increasing the concentration of sulphate anions in a sea water or diluting that sea water makes the (negative) zeta potential still more negative. Those measurements support the assumption that by brine dilution or sulphate addition, the calcite surface can become repulsive towards negative polar oil components and thus make it less oil-wet.

In their review and discussion of possible LSE mechanisms for sandstones, Jackson et al. (2016) consider that changes in the zeta potential at the mineral surfaces are an appropriate criterion to predict LSE because that potential determines the magnitude of electrostatic forces between the rock surface and polar oil components. Such zeta potential changes are involved in the three LSE mechanisms (DLE, MIE, and local $\mathrm{pH}$ change) considered predominant by the authors.

\subsubsection{The impact of crude oil composition and phase behavior}

In their extensive study, Suijkerbuijk et al. (2012) indicate that LSE are conditioned by the use of crude oil (instead of refined oil) but they did not find any specific oil characteristic exerting a predominant role on LSE, probably because such role depends also on the rock and brine under consideration. The correlation between oil recovery and brine-oil interfacial tension was the most reliable one they could identify.

Fjelde et al. (2014) studied the impact of oil composition on LSE for the case of a ferrous glauconite clayey sandstone. From the analysis of oil components in core effluents, they showed that the retention of acid components by the rock was sensitive to the injected brine salinity/composition whereas the retention of basic ones (that is stronger as clay minerals are negatively charged) was not. These observations are in line with a predominant bridging role of cations in the retention of acid polar components since the latter are negatively charged as clay sheets are also. On the contrary, positively charged basic components are subject to stronger direct adsorption that is therefore not much influenced by cations in solution. Such an interpretation was supported by rock surface characterization data by atomic force microscopy and surface plasmon resonance spectroscopy (Mugele et al., 2014) that showed that a dilution or replacement of divalent cations could induce a wettability change of clay mineral surface and weaken their role in bridging acid polar oil components and clay surface.

Mahzari and Sohrabi (2015) report a side effect of low salinity brine injection that is the formation of microdispersions of water in the oil phase. That phenomenon is invoked as possibly contributing to a wettability change of mineral surfaces since those inverse micelles may concentrate some polar compounds initially adsorbed on the rock. Such an emulsification mechanism with positive impact on oil recovery was reproduced in the micromodel experiments from Duboué et al. (2019) with a model oil system containing asphaltenes.

\subsubsection{Possible other mechanisms}

Among other less-often-invoked LSE mechanisms, one can mention the possible role of osmosis effects when a low salinity brine is injected into a rock saturated with a high-salinity connate brine. Actually, if that connate aqueous phase is discontinuous (assuming a non-waterwet rock), then those brine blobs may swell and mobilize the adjacent oil phase, as a result of water filtration across the oil-brine interfaces. That phenomenon was visualized on 2D micromodels by Sandengen et al. (2015).

\subsection{Synthesis}

Trying to summarize previous findings, LSE are explained as a whole by a modification of ionic forces binding some oil components to the rock surface and leading to their release and to an increase of rock wettability to water. Such a modification would stem from the expansion of the layer of ions interacting with the rock surface, from the reduced valence of these ions when divalent cations are replaced by monovalent ones in the injected brine, and from solution to rock ion exchanges with possible associated reactions (including soap formation through $\mathrm{pH}$ increase or dissolution of some minerals). These ion-induced modified interactions may also induce flow diversion at the pore scale in the presence of sensitive clays or when mineral reactions occur. 
Eventually, smart water effects on oil recovery would result from weakened interactions between polar oil components and the rock surface, either indirectly via a reduced ionic bridging (especially for negatively changed clayey sandstones), or directly through a detergency of polar oil components. Hence, in all cases, smart water effects are seen as a wettability change of the rock, in line with the conclusion of many authors stating that LSE concern reservoir rock-fluid systems, i.e. reservoir rocks that were aged with a crude oil in the presence of connate brine with significant TDS and/or divalent ions. To that respect, LSE can be modelled as rock wettability alteration effects as can be obtained by the injection of specific surfactants, usually named Wettability Modifiers (WM). That analogy underlies the general-purpose model that is described in a subsequent section.

\section{Discussion of dilution and cation exchange mechanisms}

From previous review, salinity effects on recovery are not systematically obtained for all Crude Oil Brine Rock (COBR) systems and should be considered as casedependent. However, DLE and/or MIE appear to be frequently responsible for LSE. Such mechanisms would be effective in both (clayey) sandstone rocks and carbonate rocks although they may involve different interactions of chemical species in solution and on the rock. However, the interplay of LSE and MIE still raises questions. In the following, we try to explain the complementary roles of brine concentration and ionic composition. To this regard, we need to analyze cation exchange mechanism and dilution mechanism separately.

\subsection{Cation exchange mechanism (MIE)}

The role of cation exchange mechanism is essential in clayey rock systems because structural deficit of positive charges in clay mineral structure leads to the adsorption of cations to ensure the electro-neutrality of the rock. These adsorbed cations can be exchanged with solution cations. Their amount can thus be quantified and constitute the Cation Exchange Capacity (CEC), which is a characteristic of each type of clay. Many studies indicate that the absence of divalent cations in the injected brine contrary to the connate brine can contribute to the increase of oil recovery by making the rock less oil-wet. So one may wonder if the so-called low salinity effects do not result primarily from a mechanism of cation exchange. However, if one considers minerals like clays, the adsorbed cations forming the CEC are necessary to guarantee clay stability, and divalent cations have a higher affinity with mineral surfaces than monovalent ones. The consequence is that brine dilution alone (at fixed relative concentration of various ions) is in favor of the retention of multivalent high-affinity cations to satisfy that CEC, which is not in favor of a wettability change towards water. This point is illustrated in Appendix where the effects of brine dilution and ionic composition on the nature and amount of adsorbed cations are calculated for a clayey rock characterized by a given CEC. Assuming that the CEC is satisfied, the ion distribution between brine and rock surface is determined as a function of the equivalent mole concentration of cations and of the equivalent mole ratio between divalent and monovalent cations in the injected brine. The main result is that due to a preferential adsorption of divalent cations on clays, the amount of adsorbed divalent cations increases when the cation concentration of the brine (also quantified by its TDS) decreases while keeping its ionic composition. Such a behavior is not in line with a favorable effect of brine dilution on oil recovery through a wettability change since divalent cations are assumed to link polar oil components (often negatively charged acidic ones) and negatively charged clayey rock surface better than monovalent cations. That is, diluting the injection brine without changing its cationic composition would not change the wettability and improve the oil recovery through the cation exchange mechanism. On the contrary, as shown also in Appendix, substituting monovalent cations for divalent cations in the injected brine reduces considerably the amount of adsorbed divalent cations with expected favorable impacts on wettability and oil recovery.

To end with, the MIE mechanism induced by the dilution of an injection brine at fixed composition does not explain the favorable low salinity effects often observed on wettability and oil recovery, at least for clayey rocks. Nevertheless, the MIE mechanism resulting from a substitution of monovalent cations for divalent cations in the injected brine would impact wettability and recovery favorably. The origin of Low Salinity Effects has to be searched in a looser interaction between the rock surface and solution electrolytes, as explained in the following.

\subsection{Double Layer Expansion (DLE) mechanism}

Considering that rock surface has a given electric charge, a layer of adsorbed ions (of opposite charge) plus an adjacent diffuse layer of ions equilibrate the rock charge. Gouy-Chapman's model (Goodwin, 2009) can be used to determine the distribution of ions in the diffuse layer of ions interacting with the rock. The same developments are used hereafter to interpret Low Salinity Effects.

According to Boltzmann distribution of ions near a surface at fixed potential $\psi_{0}$, and using Debye-Hückel solution approximation, the potential $\psi$ at distance $x$ from that surface can be approximated as:

$$
\psi=\psi_{0} e^{-\kappa x},
$$

where $\kappa$ is the Debye-Hückel parameter which is itself proportional to the square root of the ionic force $I$ defined as:

$$
I=\frac{1}{2} \sum_{j} v_{\mathrm{wj}} z_{j}^{2},
$$

with $v_{\mathrm{wj}}$ the molar concentration of ion $j$ in aqueous phase and $z_{j}$ its valence.

One can then rewrite previous potential expression as:

$$
\psi=\psi_{0} e^{-\omega \sqrt{I} x},
$$

with $\omega=\frac{\kappa}{\sqrt{I}}$ a constant at given temperature. 
For our analysis, $\psi_{0}$ is the potential close to rock surface at the limit between adsorbed ions and diffuse ion layer. $\psi_{0}$ may vary in sign and intensity from one mineral to another. For clays, cations equilibrate the negative electrical charge resulting from $\mathrm{Si}-\mathrm{Al}$ substitution in the crystalline structure. The $\mathrm{pH}$ of the solution plays a major role in determining surface charge of minerals, especially for uncharged ones.

The resulting force of interaction $f$ between the charged solid surface and ions at distance $x$ can then be estimated as the derivative of $\psi(x)$ :

$$
f=-\omega \sqrt{I} \psi_{0} e^{-\omega \sqrt{I} x} .
$$

The evolution of the module of that force $f$ with $\sqrt{I}$ can be written:

$$
\frac{\mathrm{d}|f|}{\mathrm{d}(\sqrt{I})}=\omega(1-\omega \sqrt{I} x) \psi_{0} e^{-\omega \sqrt{I} x}
$$

The intensity of the interacting force increases with the ionic force (i.e., $\frac{\mathrm{d}|f|}{\mathrm{d}(\sqrt{I})}>0$ ) at short distances $x$ such that $x<\frac{1}{\omega \sqrt{I}}$.

Inversely, for the purpose of our study, the impact of a reduction of ionic force $I$ (or of $\sqrt{I}$ ) is a decreased intensity of interaction forces in a rock-adjacent layer whose thickness $x$ increases as the inverse of $\sqrt{I}$. Furthermore, ionic force decrease may result either from a brine dilution and/or from a replacement of divalent cations by monovalent cations at the same equivalent concentration (in charge). For instance, replacing a solution of divalent cations, by a solution of monovalent cations that is equivalent in charge, divides the ionic force by $2(\sqrt{I}$ divided by $\sqrt{2}$ ). However, the dilution ratios of at least 10 generally applied have a larger impact on the ionic force than cation replacement $(\sqrt{I}$ divided by more than 3$)$.

Finally, previous model accounts for decreased interaction forces in the vicinity of rock surface when brine is diluted, and also to a lesser extent when divalent cations are replaced by monovalent ones.

To end with, the DLE mechanism could explain the Low Salinity effects through a reduced intensity of ioninduced oil-rock interaction. The assumption underlying that conclusion is that the intensity of oil-rock interactions is driven by brine electrolytes, which raises questions discussed hereafter.

\subsection{Further discussion of the model}

According to many studies reported before, the intensity of interactions between polar oil components and rock surface can be decreased through the interplay of ions via the mechanisms of ionic Double Layer Expansion (DLE) and Multi Ion Exchange (MIE). However, the type of rock, the brine composition and concentration, and the composition of crude oil determine the nature and intensity of oilrock interactions for a given field case, and, consequently, the occurrence and magnitude of LSE. In the following, we consider different rock and crude oil characteristics and attempt to explain the variability of LSE from one Crude Oil Brine Rock (COBR) system to another. Rock types and polar oil component types are characterized by their respective charges, although mixed situations can be found in reality.

For silico-clastic rocks, the clay content most often determines the specific surface area of the rock and its capacity of adsorption. The structural deficit of positive charges in clays leads to a negatively charged surface and to the adsorption of compensating cations. Those cations constitute a bridge between acidic Polar Oil Components (POC) and clay mineral surfaces. Reducing the brine concentration leads to an expansion of the layer of compensating cations (especially the diffuse layer) and consequently to weakened bridging between POC and rock, i.e. to a more water-wet state favourable to oil recovery. Replacing divalent cations by monovalent cations also weakens that bridging to a lesser extent because ionic force is reduced via valence effects. That is, brine dilution and/or composition adjustment (divalent cation replacement) are expected to increase the water wettability of silico-clastic rocks saturated with acidic crude oils. For crude oils without any acidic POC, rock wettability to oils may result from basic POC, or from uncharged components via weak interactions. Positively charged basic POC may adsorb directly on the rock surface as suggested by Fjelde et al. (2014), without requiring any cation bridging. LSE would then either be insignificant or involve other mechanisms such as the substitution of specific cations for these adsorbed basic POC. The effects of a brine dilution (DLE) and of a replacement of divalent cations (MIE) should then not be in favour of an elimination of these adsorbed POC, except if ionic force reduction reduces the capacity of the rock to adsorb POC, through a reduced occupancy of rock surface by repulsion of charged POC heads (a well-known effect of salinity on surfactant adsorption). Previous considerations confirm again that LSE can hardly be predicted for any COBR system, probably often because of an insufficient characterization of the crude oil composition.

Considering now carbonate rocks, mineral surfaces are positively charged at neutral $\mathrm{pH}$ conditions. Therefore, the role of brine ions should be opposite to that observed in clayey rocks for a given crude oil. We consider again the dominant presence of acidic POC then of basic ones in the crude oil. In the presence of an acidic polar crude oil, ionic force reduction should then have little impact on rock wettability, since acidic POC are directly and tightly adsorbed on the rock. However, sensitive effects of brine dilution in carbonates are reported by many authors, Yousef et al. (2011) for instance. Other factors of improved oil recovery in carbonates are also invoked, such as the role of rock dissolution and anion substitution. The latter concerns sulphate anions in particular. Indeed, the replacement of a connate brine mainly containing monovalent anions by a sulphate-rich injection brine like a seawater leads most often to a reduction of residual oil saturation. As already evoked, salinity reduction could also contribute to a reduction of the rock capacity of adsorption for POC directly adsorbed on the rock such as acidic ones on carbonates. In the presence of basic POC in the crude oil, one could expect anions to play the role of a bridge between those basic components and carbonate rock surface of same 
Table 1. Possible mechanisms of rock wettability change by injected brine, depending on rock and crude oil polarities

\begin{tabular}{|c|c|c|}
\hline Polar Oil Components (POC) & $\begin{array}{l}\text { Negatively charged rock } \\
\text { surface (clayey rocks) }\end{array}$ & $\begin{array}{l}\text { Positively charged rock } \\
\text { surface (carbonates) }\end{array}$ \\
\hline \multicolumn{3}{|l|}{ Acidic POC } \\
\hline POC-rock interaction & Cation bridging & Direct adsorption \\
\hline Wettability modification through & $\begin{array}{l}\text { Ionic force decrease: brine dilution } \\
\text { (plus cation valence reduction) }\end{array}$ & $\begin{array}{c}\text { Anion substitution }\left(\mathrm{SO}_{4}^{2-}\right) \text { OR reduced } \\
\text { POC adsorption capacity at low ionic } \\
\text { force }\end{array}$ \\
\hline \multicolumn{3}{|l|}{ Basic POC } \\
\hline POC-rock interaction & Direct adsorption & Anion bridging \\
\hline Wettability modification through & $\begin{array}{l}\text { Cation substitution OR reduced POC } \\
\text { adsorption capacity at low ionic force }\end{array}$ & $\begin{array}{l}\text { Ionic force decrease: brine dilution } \\
\text { (plus cation valence reduction) }\end{array}$ \\
\hline
\end{tabular}

charge, as do cations for clayey rocks in the presence of acidic POC. Decreasing that bridging and increasing water wettability could then result from a brine dilution.

Above discussion of crude oil-rock interactions is summarized in Table 1. Although it is simplistic with regard to the complexity of crude oil-rock interactions, it shows that the origin of low salinity effects cannot be attributed to the same mechanisms according to the polarity of crude oil-rock system under consideration. Furthermore, the interpretation of salinity effects especially for non-polar crude oils (i.e., with very low acid or base numbers) does not fall into any category of Table 1.

To end with, the diversity of rock-fluids systems and their insufficient compositional characterization render LSE prediction hazardous. For that reason, simulation models of Low Salinity waterflooding cannot claim to predict LSE prediction a priori. They remain fairly empirical, and are essentially designed for matching and interpreting reference coreflooding experiments, as a required step for injection brine optimization.

\section{Simulating low salinity effects}

Existing models for simulating low salinity effects are based on the assumption of a wettability alteration of the rock that entails a modification of two-phase flow parameters. Our model for LSE involves also wettability-dependent two-phase flow parameters. It is generic however because wettability alteration can stem from other processes than low salinity water injection, such as surfactant injection. The implementation of this generic model is part of a patented methodology for assessing LSE from laboratory experiments (Bourbiaux and Nguyen, 2018), and will be subject of a future communication.

Main specifications of existing models for LSE are summarized before developing ours.

\subsection{Existing models for LSE simulation}

Most existing models simulate presumed low salinity effects on wettability and recovery through a dependence on salinity of relative permeability functions including saturation end-points, and possibly also a dependence on salinity of capillary pressure function.

Jerauld et al. (2008) published the general basis for that modelling approach recalled hereafter. The residual oil saturation, $S_{\text {orw }}$, is allowed to vary between a maximum value $S_{\text {orw }}^{\mathrm{HS}}$ (at High Salinity [HS]) and a minimum value $S_{\text {orw }}^{\mathrm{LS}}$ (at Low Salinity [LS]), and two sets of $k_{r}-P c$ curves are defined respectively at HS and at LS. At any salinity comprised between LS and HS, any $k_{r}$ or $P c$ value is linearly interpolated between its value at $\mathrm{HS}$ and its value at LS as a function of the reduction of $S_{\text {orw }}$ scaled between its value at HS and its value at LS. That is, denoting respectively $S_{\text {orw }}^{\mathrm{LS}}$ and $S_{\text {orw }}^{\mathrm{HS}}$ the residual oil saturation values at LS and HS, Jerauld et al.'s model for water-oil two-phase flow properties collectively denoted $f_{\text {ow }},\left(f_{\text {ow }}=k_{\mathrm{rw}}, k_{\text {row }}, P_{\text {cow }}\right)$ is formulated as:

$$
f_{\mathrm{ow}}=\theta f_{\mathrm{ow}}^{\mathrm{HS}}\left(S^{*}\right)+(1-\theta) f_{\mathrm{ow}}^{\mathrm{LS}}\left(S^{*}\right),
$$

with

$$
\theta=\frac{S_{\text {orw }}-S_{\text {orw }}^{\mathrm{LS}}}{S_{\text {orw }}^{\mathrm{HS}}-S_{\text {orw }}^{\mathrm{LS}}}
$$

$S^{*}=\frac{S_{0}-S_{\text {orw }}}{1-S_{\text {wi }}-S_{\text {orw }}}$ the scaled oil saturation and $S_{\mathrm{wi}}$ the connate water saturation.

In most reported simulation studies to date, LSE are modelled by the only modification of relative permeabilities including saturation endpoints especially $S_{\text {orw }}$. Capillary pressure modification is often ignored at field scale, although that simplification may be questioned for fractured reservoirs, where capillary pressure plays a determinant role in oil expulsion from matrix blocks.

More recently, comprehensive multi-component reactive transport models were developed (Dang et al., 2013; Qiao et al., 2014) to further identify the origin of rock wettability change responsible for $\left(k_{r}, P c\right)$ modification and recovery increase. Qiao et al.'s model (2014) was designed to simulate LSWI in carbonates; in that model, $k_{r}$ and $P c$ functions are interpolated between the respective oil-wet and water-wet functions with a wettability index as interpolant. The latter is a function of rock surface concentration in several chemical species, divalent cations, sulphate anions, and polar oil components (carboxylic 
group). Dang et al.'s model (2013) was used to match corefloods in sandstones via an interpolation of $k_{r}$ functions alone with $\mathrm{Ca}^{2+}$ equivalent fraction as interpolant. Al-Shalabi et al. (2014) interpreted low salinity experiments from Yousef et al. (2011) using UTCHEM and PHREEQC geochemical models, in order to find out the most probable involved mechanism, which turned out to be a change of rock surface charge rather than a dissolution of anhydrite.

These few modelling studies indicate that LSE can be reproduced numerically through a relationship between two-phase flow parameters $\left(k_{r}, P c\right.$ functions including saturation endpoints) and a wettability driver whose value depends on the nature and concentration of ionic species and oil components. They confirm that salt dilution is not the sole mechanism involved in LSE.

\subsection{A generic wettability alteration model}

Our model integrates the modification of flow parameters that results from a wettability change, whatever the implied recovery process that may be either a LSWI or the chemical injection of specific surfactants usually named Wettability Modifiers (WM). LSWI is simulated with a model of LSE based on the ionic force, in addition to the empirical modelling approach based on salt concentration. Flow parameters include water-oil relative permeability functions, water-oil capillary pressure function, residual oil saturation, and irreducible/minimum water saturation.

Whereas LSWI does not involve any significant change in the water-oil interfacial tension, injection of a WM generally implies an IFT decrease that is significant (reduction that may be 10-fold) compared to that of LSWI. Then, for latter situation, the proposed model incorporates IFT effects on flow parameters. The simulation of such combined effects of a wettability reduction and of an IFT reduction will not be detailed in this paper dedicated to salinity effects.

So, regarding the simulation of low salinity effects, two extreme wettability states, initial state at usually high salinity (labelled $H$ ) and modified state at a low salinity (labelled $L$ ) are defined through the input of respective flow parameters. Whereas initial flow parameters describe the injection of initial high-salinity brine, modified flow parameters describe the injection of a brine at the minimum (low) value of the salinity interval over which recovery is modified. Regarding WM injection, initial, and modified flow parameters model the injection respectively of a brine without WM and of a brine at a prescribed concentration of injected WM.

We denote $G$ any flow parameter at an arbitrary stage of brine oil displacement. That is, $G$ stands for saturation endpoints $S_{\text {orw }}$ or $S_{\text {wi }}$, or water (oil) relative permeability $k_{\mathrm{rw}}\left(k_{\mathrm{ro}}\right)$ or water-oil capillary pressure $P c_{\mathrm{ow}}$ values at current saturation value. $G$ is interpolated between its value in the initial state of wettability and its value in the modified state. For any given flow parameter $G$, that interpolation involves an interpolant that is a power function of the scaled physical variable, denoted $V$, that drives wettability change. For a LSWI, the physical variable, is either the global salinity (Total Dissolved Salts) or the square root of the corresponding ionic force $I$. For a surfactant injection, the physical variable is the amount of additive that is adsorbed on the rock assuming that wettability modification by surfactant is similar to an adsorption process of that agent. Variable is scaled with respect to salinity (or $\sqrt{I}$ ) interval or adsorption at the maximum injected concentration of additive.

That can be simply formulated as:

$$
G(V)=[V]^{\beta_{G}} G^{L}+\left(1-[V]^{\beta_{G}}\right) G^{H},
$$

with $\beta_{G}$ the exponent of interpolant function referring to flow parameter $G$, and $V$ equal to

$$
\begin{aligned}
& V=\frac{\mathrm{TDS}_{H}-\mathrm{TDS}}{\mathrm{TDS}_{H}-\mathrm{TDS}_{L}} \text { for global salinity modelling approach, } \\
& V=\frac{\sqrt{I_{H}}-\sqrt{I}}{\sqrt{I_{H}}-\sqrt{I_{L}}} \text { for ionic force modelling approach, } \\
& V=\frac{R_{\text {adds }}\left(C_{\mathrm{WM}}\right)}{R_{a d s}\left(C_{\mathrm{WM}-\mathrm{inj}}\right)} \text { for a Wettability Modification }(\mathrm{WM}) \text { by } \\
& \text { a surfactant, }
\end{aligned}
$$

with $C_{\mathrm{WM}-\text { inj }}$ and $C_{\mathrm{WM}}$ the injected additive concentration and the current concentration respectively, and $R_{\text {ads }}\left(C_{\mathrm{WM}}\right)$ the amount of adsorbed surfactant on the rock at equilibrium with a solution at concentration $C_{\mathrm{WM}}$.

Whereas global salinity (TDS) driver can be used to match LSE empirically through the use of convenient exponents $\beta_{G}$, the ionic force driver has a theoretical basis that accounts for the mechanism of ionic Dual Layer Expansion (DLE) triggered by brine dilution and by ion valence reduction to a lesser extent.

The low salinity waterflooding results from Yousef et al. (2011) would support the choice of the square root of ionic force as a driver of $S_{\text {orw }}$ reduction rather than global salinity, as illustrated by Figure 1. The evolution of residual oil saturation in two restored carbonate composite cores with seawater dilution is drawn versus total salinity (Fig. 1, left hand) and versus the square root of ionic force (Fig. 1, right hand). One observes that $S_{\text {orw }}$ is modified proportionally to the square root of ionic force within the interval of sensitivity of $S_{\text {orw }}$ to injected brine salinity. The evolution of $S_{\text {orw }}$ with TDS shows a somewhat poorer linear correlation. Drawing conclusion may be hazardous however because the relation between residual oil saturation and salinity-dependent rock wettability is far from straightforward. In addition, one must be aware that only dilution effect is considered in that study. Since $I$ and TDS are changed proportionally in a dilution process, the improved correlation reflects the benefit of square root representation. That observation is in line with the theoretical model of rock-brine ionic interaction presented in the previous section.

\subsection{Calibrating model from laboratory corefloods}

Whereas the model is expected to predict the trend in the evolution of flow properties with salinity, it has still to be calibrated from laboratory corefloods in order to define the amplitude of flow properties modifications with salinity, including the range of salinity over which those flow properties are modified. For a given reservoir case, corefloods consist of the waterflooding of restored cores by injection brines of different concentrations and/or compositions. To restore the original wettability, cores have to be saturated 

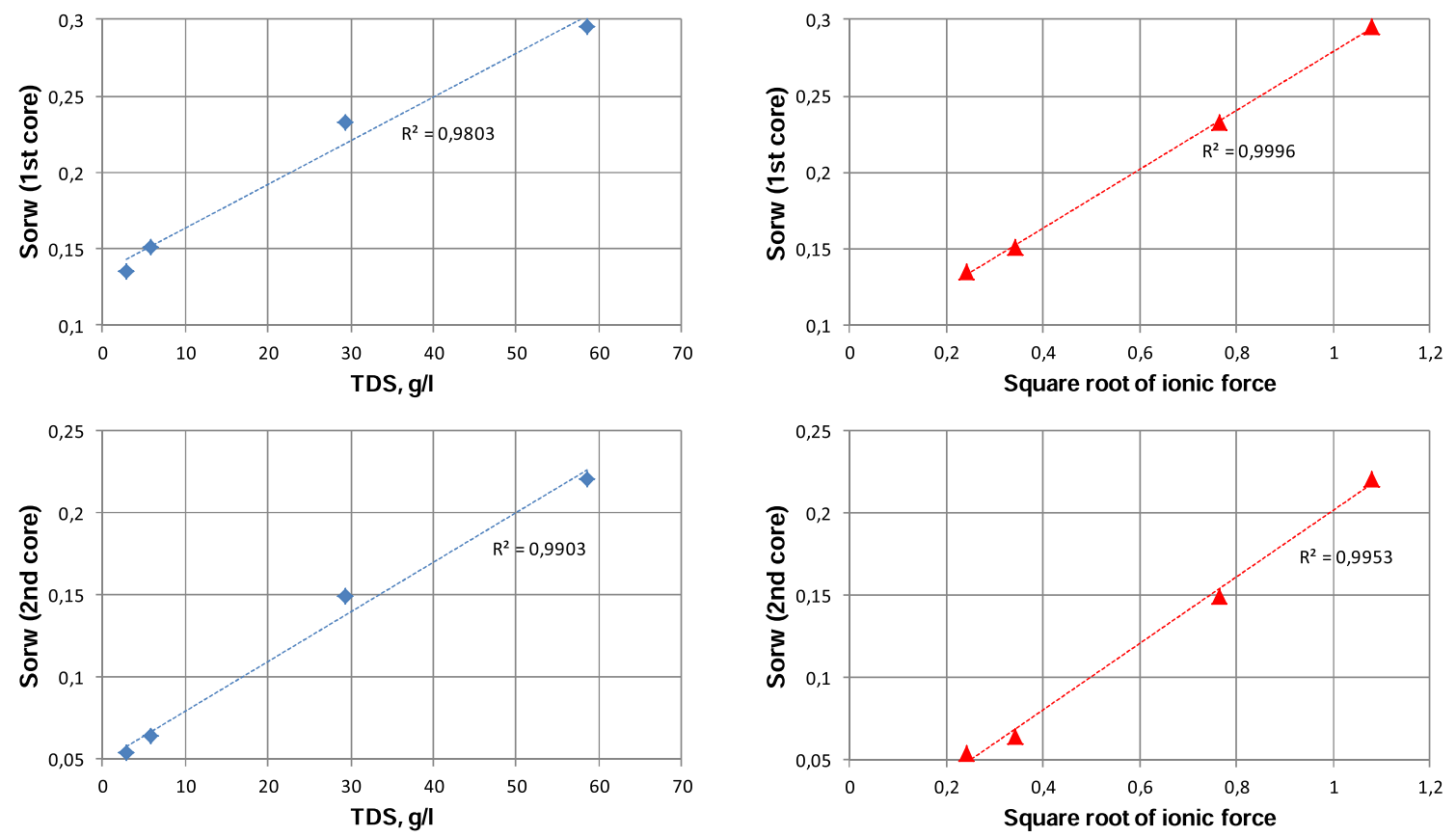

Fig. 1. Analysis of Yousef et al. (2011) coreflood data (two composite cores): evolution of $S_{\text {orw }}$ versus Total Dissolved Salts (TDS) and versus the square root of ionic force $(\sqrt{I})$.

with crude oil and connate brine then aged at conditions (temperature) as close to reservoir conditions as possible. Next, they are subjected to a secondary waterflooding by the available brine for water injection, such as seawater, before being successively flooded by gradually diluted brines of same composition, and sometimes by brines of modified ionic composition. At each salinity/composition step, the pressure drop along the core and the oil production are measured until a steady state is established. Above procedure is the most common one found in published LSE assessment studies.

Let us for instance consider waterflooding experiments with gradually diluted brines of given composition, i.e. brines only characterized by their respective concentrations (TDS). The cumulated oil produced at a given salinity step gives access to the apparent residual oil saturation at core scale, $S_{\text {orw }}^{\mathrm{CORE}}$ (TDS), and the stabilized pressure drop gives access to the water relative permeability end-point value, $k_{\mathrm{rw} \max }^{\mathrm{CORE}}(\mathrm{TDS})$, at the salinity TDS under consideration. Assuming core homogeneity and negligible capillary pressure in first approximation, $S_{\text {orw }}^{\mathrm{CORE}}(\mathrm{TDS})$ is equal to the effective residual oil saturation at pore scale, $S_{\text {orw }}$ (TDS).

Keeping previous notations, $\operatorname{TDS}_{H}$ and $\operatorname{TDS}_{L}$ are respectively the values of TDS above which and below which no sensitivity of flow properties (in practice, residual oil saturation) is observed. The corresponding residual oil saturation values at those two upper and lower limits of salinity sensitivity range are $S_{\text {orw }}^{H}$ and $S_{\text {orw }}^{L}$, and the corresponding water relative permeability values are $k_{\text {rw } \max }^{H}$ and $k_{\mathrm{rw} \max }^{L}$. Most often, one considers that the salinity of the initial brine used for water injection corresponds to the upper limit of sensitivity $\operatorname{TDS}_{H}$, however, this may not be the case.
So, the sequence of experiments over a wide range of decreasing concentrations of the injected brine yields the following experimental data to calibrate the model for LSE: $\operatorname{TDS}_{H}, \mathrm{TDS}_{L}$, and $S_{\text {orw }}(\mathrm{TDS})$ and $k_{\text {rw } \max }(\mathrm{TDS})$ for different TDS values including $\operatorname{TDS}_{H}, \mathrm{TDS}_{L}$, and a few intermediate values.

To predict those discrete experimental data, the global salinity model specified before has to satisfy the following equations:

$$
\begin{gathered}
S_{\text {orw }}(\mathrm{TDS})=\overline{\mathrm{TDS}}^{\beta_{\text {Sorw }}} S_{\text {orw }}^{L}+\left(1-\overline{\mathrm{TDS}}^{\beta_{\text {Sorw }}}\right) S_{\text {orw }}^{H}, \\
k_{\mathrm{rw} \mathrm{max}}(\mathrm{TDS})=\overline{\mathrm{TDS}}^{\beta_{\mathrm{kww}}} k_{\mathrm{rw} \mathrm{max}}^{L}+\left(1-\overline{T D S}^{\beta_{\mathrm{krw}}}\right) k_{\mathrm{rw} \mathrm{max}}^{H},
\end{gathered}
$$

where $\overline{\mathrm{TDS}}$ is the salinity scaled over the interval of flow properties sensitivity to TDS,

$$
\overline{\mathrm{TDS}}=\frac{\mathrm{TDS}_{H}-\mathrm{TDS}}{\mathrm{TDS}_{H}-\mathrm{TDS}_{L}} .
$$

Model input data include:

- The upper and lower limits $\operatorname{TDS}_{H}, \mathrm{TDS}_{L}$ of concentration interval over which flow properties $\left(S_{\text {orw }}, k_{r}\right.$, etc.) are sensitive to injected salinity (note that this interval may be narrower than the interval of injected salinities).

- The corresponding oil saturation end-points, $S_{\text {orw }}^{H}$ and $S_{\text {orw }}^{L}$.

- The experimental values of corresponding water $k_{r}$ end-points, $k_{\mathrm{rw} \max }^{H}$ and $k_{\mathrm{rw} \max }^{L}$.

Model calibration concerns exponents $\beta_{\text {Sorw }}$ and $\beta_{\text {krw }}$ of the weighting power functions of salinity driver. This is 
done through a linear regression of scaled variables in logarithmic scale as follows. Actually, from previous expression of $S_{\text {orw }}(T D S)$, one infers:

$$
\overline{\operatorname{TDS}}^{\beta_{\text {Sorw }}}=\overline{S_{\text {orw }}},
$$

with

$$
\overline{S_{\text {orw }}}=\frac{S_{\text {orw }}^{H}-S_{\text {orw }}(\mathrm{TDS})}{S_{\text {orw }}^{H}-S_{\text {orw }}^{L}},
$$

which leads to the following value of $\beta_{\text {Sorw }}$ :

$$
\beta_{\text {Sorw }}=\frac{\operatorname{Ln}\left[S_{\text {orw }}\right]}{\operatorname{Ln}[\text { TDS }]},
$$

for $\operatorname{TDS}_{L}<\mathrm{TDS}<\operatorname{TDS}_{H}$.

A linear regression of $\operatorname{Ln}\left[S_{\text {orw }}\right]$ versus $\operatorname{Ln}[\mathrm{TDS}]$ provides the value of $\beta_{\text {Sorw }}$.

The same simple method is applied to determine the value of $\beta_{\text {krw }}$ straightforwardly. Other $\beta$ values, referring to the oil relative permeability in particular, can be adjusted by matching the transient values of production and pressure drop if recorded. However, modelling the residual oil saturation evolution with salinity is the main information expected from laboratory corefloods.

If one adopts ionic force modelling approach that is more physical, the determination of exponents $\beta_{\text {Sorw }}$ and $\beta_{\text {krw }}$ remains the same, with $\overline{\text { TDS }}$ replaced by $\overline{\sqrt{I}}=\frac{\sqrt{I_{H}}-\sqrt{I}}{\sqrt{I_{H}}-\sqrt{I_{L}}}$.

Application to the two corefloods $S_{\text {orw }}$ results reported by Yousef et al. (2011) is shown in Figure 2. The salinity interval of sensitivity is limited at a dilution factor of the injected sea water equal to 20 . For the first coreflood, the evolution of scaled $S_{\text {orw }}$ reduction (i.e., $\overline{S_{\text {orw }}}$ ) follows that of scaled $\sqrt{I}$ (i.e., $\overline{\sqrt{I}}$ ), that is, $\beta_{\text {Sorw }}$ is close to unity $(0,9)$. The evolution of $\overline{S_{\text {orw }}}$ with $\overline{\mathrm{TDS}}$ as the salinity driver is not linear and the corresponding $\beta_{\text {Sorw }}$ value is comprised between 1,5 and 2. However, for the second coreflood, the evolution of $S_{\text {orw }}$ results with salinity is matched with a $\beta_{\text {Sorw }}$ value close to unity, whatever the salinity driver $(\overline{\mathrm{TDS}}$ or $\overline{\sqrt{I}}$ ). Further validation of ionic force parameterization would require experiments with a denser scanning of the salinity range.

The results for a sandstone reservoir case published by Fjelde et al. (2012) are also analyzed. For that case, a Formation Water (FW) was injected, followed by seawater, then by FW diluted 100 times and finally by FW diluted 1000 times. Insignificant $S_{\text {orw }}$ decrease during the last injection step leads us to limit the salinity interval of sensitivity to the last but one salinity. Figure 3, analogous to Figure 2, shows that the evolution of $\overline{S_{\text {orw }}}$ follows that of $\overline{\sqrt{I}}$ with a $\beta_{\text {Sorw }}$ value $(1,2)$ close to unity, whereas $\beta_{\text {Sorw }}$ value is nearly twice as much $(2,1)$ using TDS as the salinity driver.

The same analysis is shown in Figure 4 for the injection of a gradually diluted seawater injected in a Middle East carbonate (Zhang and Sarma, 2012). Again, $S_{\text {orw }}$ decrease follows that of the ionic force square root better than the decrease of total salinity, even if the fit is not so good as in previous cases. The final injection of a sulphate-enriched non-diluted seawater is not integrated in the analysis since
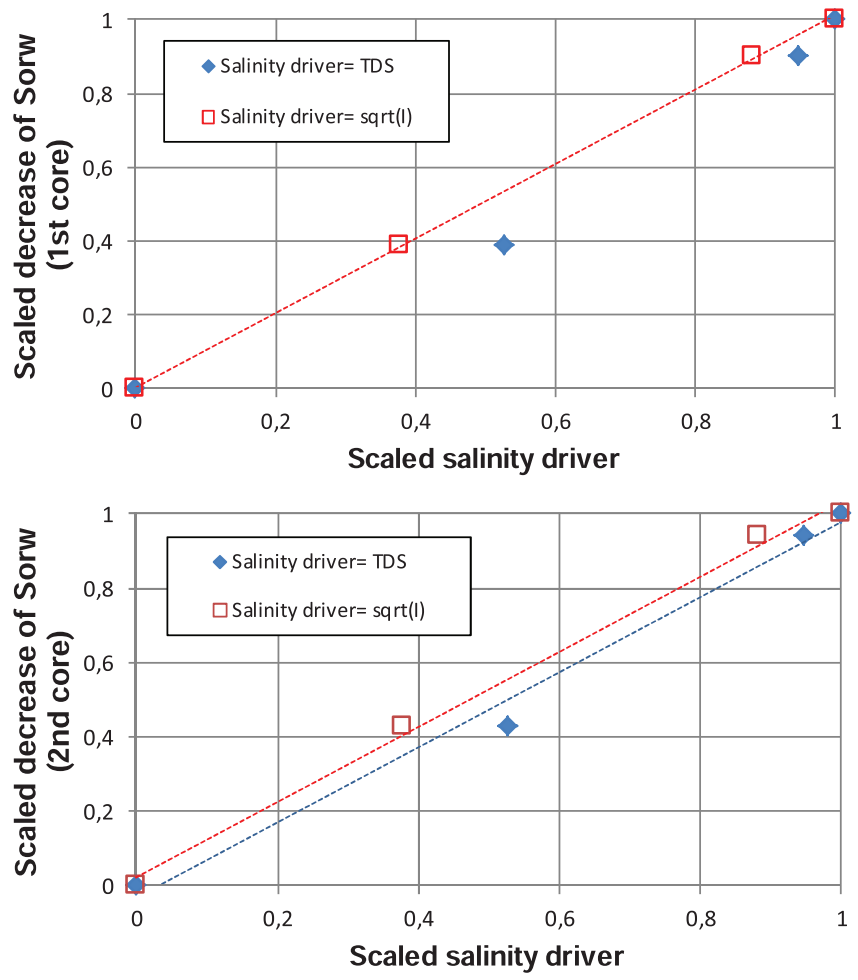

Fig. 2. Analysis of Yousef et al. (2011) results: $\overline{S_{\text {orw }}}$ evolution versus $\overline{\mathrm{TDS}}$ or $\overline{\sqrt{I}}$ (scaled salinity drivers).

its effect on oil recovery is related to another mechanism than ionic force reduction.

Finally, the analysis of brine dilution effect was attempted for another carbonate case from Romanuka et al. (2012). However, brine salinity effects were assessed via spontaneous imbibition and not via forced waterflooding in this study. We selected the only sequence of imbibitions where sulphate concentration was kept constant, with a salinity decreasing by the mixing of a formation water with an aquifer water. Although interpretation requires caution due to very few experimental data, one observes that the evolution of residual oil saturation no more follows the decrease of total salinity or of ionic force square root, even if the latter seems more appropriate than the former (Fig. 5). A possible reason for that poor correlation lies in the experimental method adopted in that study. Indeed, the modification of rock wettability in a spontaneous imbibition process is conditioned by the penetration of brine into the cores, which is only possible through a diffusion process if the rock is oil-wet. The slowness of that process may entail some incertitude on results.

Above simple procedure to calibrate the model is valid if capillary effects are negligible at core scale, and the saturation profile at the end of each salinity step of brine injection is uniform. On the contrary, for low-permeability porous media and/or low injection flow rates, some mobile oil is retained by capillary forces within the core if oil-wet or partly oil-wet. The amount of retained oil increases in the downstream part of the core and its relative impact on the average core saturation measured at steady state is all 


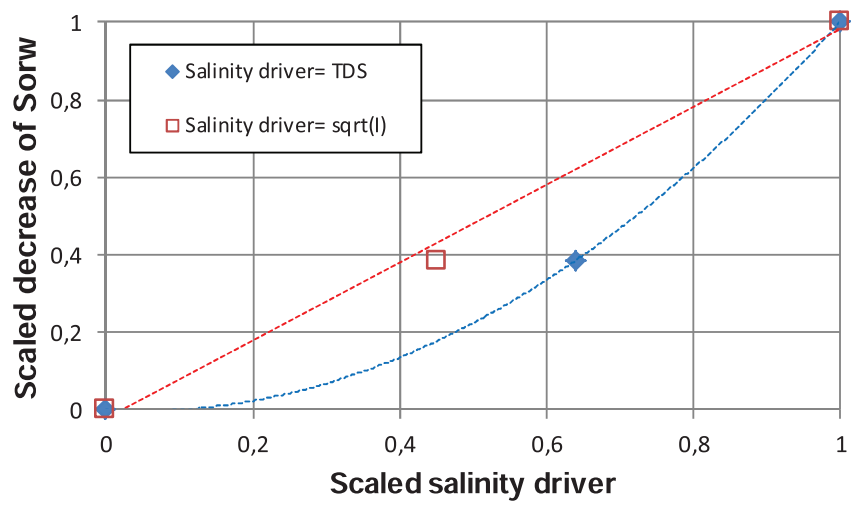

Fig. 3. Analysis of Fjelde et al. (2012) composite core 1 results: $\overline{S_{\text {orw }}}$ evolution versus $\overline{\text { TDS }}$ or $\overline{\sqrt{I}}$ (scaled salinity drivers)

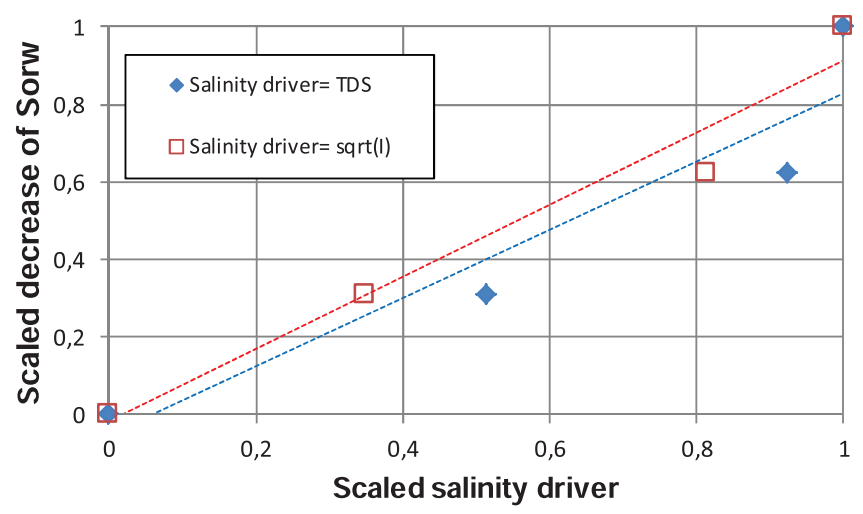

Fig. 4. Analysis of Zhang and Sarma (2012) coreflood CF3 results: $\overline{S_{\text {orw }}}$ evolution versus $\overline{\mathrm{TDS}}$ or $\overline{\sqrt{I}}$ (scaled salinity drivers)

the higher as the flow rate is lower and the core length smaller. These capillary end effects can induce a significant error on the assessment of $S_{\text {orw }}$ evolution with injected brine salinity if $S_{\text {orw }}$ is determined as the average core saturation calculated from oil production data at steady state. That issue has been underlined by Skauge (2013).

To overcome that difficulty and determine the actual pore-scale residual oil saturation at each step of brine floods at different salinities, either local saturation profiles of the core must be measured or a method based on a priori simulation and analytical scaling can be applied. The latter method is valuable as it allows one to correctly process usual coreflood data. It consists in performing a simulation of brine flood assuming that the pore-scale (microscopic) residual oil saturation, denoted $S_{\text {orw }}^{\text {SIM }}$, is equal to the experimental average core oil saturation determined from production data at steady state, denoted $S_{\mathrm{o}}^{\mathrm{CORE}}$. In addition, capillary effects are taken into account in that simulation through the input of the core brine-oil capillary pressure. Then, the simulated average oil saturation of the core, denoted $S_{\mathrm{o}}^{\mathrm{CORE}-\mathrm{SIM}}$, is calculated from the simulated saturation profile at steady state. That simulated saturation profile, computed over $\left[S_{\mathrm{wi}} ; 1-S_{\mathrm{o}}^{\mathrm{CORE}}\right]$ saturation interval, is

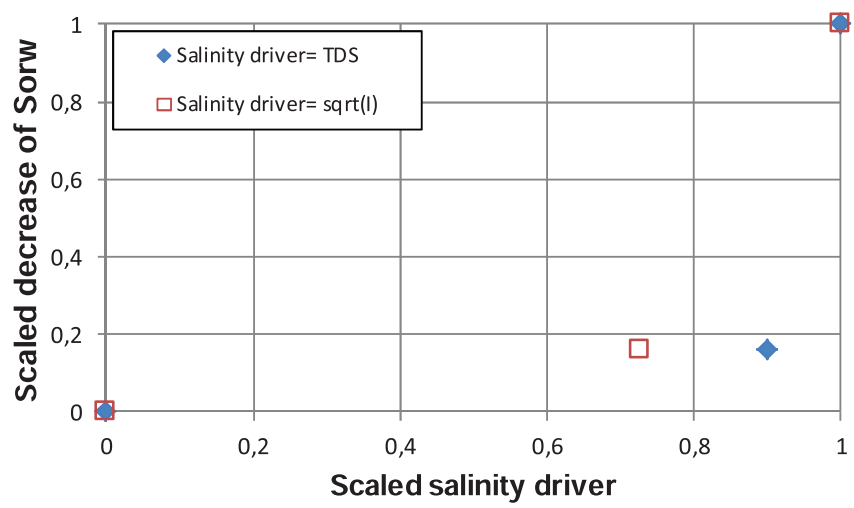

Fig. 5. Analysis of Romanuka et al. (2012) spontaneous imbibition results on limestone cores $3.2: \overline{S_{\text {orw }}}$ evolution versus $\overline{\mathrm{TDS}}$ or $\overline{\sqrt{I}}$ (scaled salinity drivers)

homothetic to the actual core saturation profile defined over $\left[S_{\text {wi }} ; 1-S_{\text {orw }}\right]$ saturation interval, with $S_{\text {orw }}$ the actual porescale residual oil saturation to be determined. That is, the scaled simulated saturation profile and the scaled core saturation profile are identical (assuming that capillary end effects do not extend beyond core length). This implies also that the simulated average core saturation $\left(S_{\mathrm{o}}^{\mathrm{CORE}-\mathrm{SIM}}\right)$ scaled over $\left[S_{\mathrm{wi}} ; 1-S_{\mathrm{o}}^{\mathrm{CORE}}\right]$ water saturation interval is equal to the experimental average core saturation $\left(S_{\mathrm{o}}^{\mathrm{CORE}}\right)$ scaled over $\left[S_{\mathrm{wi}} ; 1-S_{\mathrm{orw}}\right]$ saturation interval, which can be written as:

$$
\frac{S_{\mathrm{o}}^{\mathrm{CORE}-\mathrm{SIM}}-S_{\mathrm{ow}}^{\mathrm{SIM}}}{1-S_{\mathrm{wi}}-S_{\mathrm{orw}}^{\mathrm{SIM}}}=\frac{S_{\mathrm{o}}^{\mathrm{CORE}}-S_{\mathrm{orw}}}{1-S_{\mathrm{wi}}-S_{\mathrm{orw}}},
$$

with

$$
S_{\text {orw }}^{\mathrm{SIM}}=S_{\mathrm{o}}^{\mathrm{CORE}} .
$$

From previous equation, we infer the actual value of (porescale) residual oil saturation, $S_{\text {orw }}$, as:

$$
S_{\text {orw }}=\frac{\left(2 S_{\mathrm{o}}^{\mathrm{CORE}}-S_{\mathrm{o}}^{\mathrm{CORE}-\mathrm{SIM}}\right)\left(1-S_{\mathrm{wi}}\right)-\left(S_{\mathrm{o}}^{\mathrm{CORE}}\right)^{2}}{\left(1-S_{\mathrm{wi}}-S_{\mathrm{o}}^{\mathrm{CORE}-\mathrm{SIM}}\right)}
$$

Such a correction for deriving $S_{\text {orw }}$ from core average saturation data $S_{\mathrm{o}}^{\mathrm{CORE}}$ has to be applied to any intermediate or oil-wet rock situation in order to account for oil retention at downstream core end, even if that end effect can be minimized under high flow rate conditions.

To conclude, the modelling methodology discussed in this section will be subject of a future communication dedicated to the simulation of low salinity injection experiments.

\section{Conclusion}

The outcome of that study is twofold, first a physical interpretation of salinity effects on waterflood recovery efficiency for various rock-fluid systems in the light of published studies, second a modelling approach to simulate and reliably interpret laboratory corefloods that remain necessary 
to optimize the water injection brine dedicated to any new reservoir case.

The analysis of published case studies indicates that favorable Low Salinity Effects on recovery performance would stem from a modification of combined interactions of ions and polar oil components with the rock mineral surface. As suggested by numerous experimental facts such as zeta-potential measurements, an electrostatic view of interactions between the rock and electrolytes and organic components is proposed to explain brine dilution effects:

- For rocks and crude oil components of same charge, a model based on brine ionic force driving Double Layer Expansion (DLE) mechanism can account for a weakening of the ionic bridging between oil components and the rock, resulting in a higher wettability to water and improved oil recovery.

- For rocks and crude oil components of opposite charge, the role played by salts on the direct adsorption of polar oil components on the rock might explain a reduced oil wettability of the rock when ionic force decreases, although such a mechanism for LSE does not seem to have been reported in the literature.

The role played by the Multi Ion Exchange (MIE) mechanism is clarified, at least for clayey rocks. Indeed, the exchange of adsorbed cations induced by the sole dilution of brine does not contribute favorably to wettability and recovery. Nevertheless, the MIE mechanism resulting from a substitution of monovalent cations for divalent cations in the injected brine has favorable effects on wettability and recovery. That cation substitution contributes also to the DLE mechanism but to a lesser extent than brine dilution does.

Nevertheless, the mechanisms underlying LSE require to be investigated further and validated for a wide variety of rocks and crude oils, in particular for carbonates. Actually, a mechanism of detergency, i.e. substitution of some ions for adsorbed oil components, is also invoked for carbonates where sulphate anions improve the oil recovery in many cases where a (sulphate-rich) sea water is used. Mineral dissolution and fines migration are also invoked on a case-by-case basis. And situations remain where low salinity injection has little or no favorable impact on oil recovery.

For this reason, the optimization of an injection brine for a given oil reservoir requires a laboratory investigation with the rock-fluids system under consideration, and a modelling of coreflooding results for subsequent reservoir application. The generic model proposed in this paper is based on a modification of flow properties (including $S_{\text {orw }}$ ) versus a wettability driver that may be either the global salinity or the square root of ionic force $(\sqrt{I})$ when low salinity water injection is simulated. This model involves very few calibration parameters that can be easily predetermined from experimental data. The ionic-force-based wettability driver enables one to test the validity of DLE as the main mechanism responsible for LSE. Actually, the analysis of some published results showed that the scaled residual oil saturation could then be estimated as the scaled value of $\sqrt{I}$.
Furthermore, a straightforward method of determination of the actual residual oil saturation from core-scale production data is proposed to take into account capillary end effects that may otherwise lead to erroneous interpretations of low salinity effects on oil recovery.

Yet, the effects of brine composition and concentration on a waterflooding still raise unsolved questions regarding specific rock-fluid systems. One may expect that the cumulated knowledge gained from the physical and numerical interpretation of well-documented case studies will gradually improve our ability to design a customized injection brine upon pertinent characterization of COBR system.

\section{References}

Alroudhan A.R., Vinogradov J., Jackson M.D. (2015) Zeta potential in carbonates at reservoir conditions - application to IOR, in: Paper We B06 Presented at the 18th European Symposium on IOR, Dresden, Germany, 14-16 April.

Al-Shalabi E.W., Sepehrnoori K., Pope G. (2014) Geochemical interpretation of low salinity water injection in carbonate oil reservoirs, in: Paper SPE 169101 Prepared for the SPE IOR Symposium held in Tulsa, USA, 12-16 April.

Austad T., RezaeiDoust A., Puntervold T. (2010) Chemical mechanism of low salinity water flooding in sandstone reservoirs, in: Paper Prepared for the SPE IOR Symposium held in Tulsa, OK, USA, 24-28 April.

Austad T., Shariatpanahi S.F., Strand S., Black C.J.J., Webb K.J. (2012) Conditions for a low-salinity Enhanced Oil Recovery (EOR) effect in carbonate oil reservoirs, Energy Fuels 26, 569-575.

Bazin B., Labrid J. (1991) Ion exchange and dissolution/ precipitation modeling: Application to the injection of aqueous fluids into a reservoir sandstone, in: SPE Reservoir Engineering, May 1991, pp. 233-238.

Bourbiaux B., Nguyen Q.L. (2018) Procédé de récupération d'hydrocarbures dans un réservoir géologique par injection d'eau faiblement saline. INPI No. 18/60.212.

Dang C.T.Q., Nghiem L.X., Chen Z., Nguyen Q.P. (2013) Modeling low salinity waterflooding: Ion exchange, geochemistry and wettability alteration, in: Paper SPE 166447 Presented at the SPE ATCE, New Orleans, Louisiana, USA, 30 September-2 October.

Duboué J., Bourrel M., Dusautoir T., Santanach E., Klimenko A., Agenet N., Boupat-Passade N., Lequeux F. (2019) Relevance of water-oil interfacial structure to low salinity oil recovery process, in: Paper P15 Presented at the 20th European Symposium on IOR, Pau, 8-11 April.

Fattahi Mehraban M., Ayatollahi S., Sharifi M. (2019) Role of divalent ions, temperature, and crude oil during water injection into dolomitic carbonate oil reservoirs, Oil Gas Sci. Technol. - Rev. IFP Energies nouvelles 74, 36. doi: $10.2516 /$ ogst/2019003.

Fjelde I., Asen S.V., Omekeh A. (2012) Low salinity water flooding experiments and interpretation by simulations, in: Paper SPE 154142 Presented at the 18th SPE IOR Symposium, Tulsa, OK, USA, April 14-18.

Fjelde I., Omekeh A.V., Sokama-Neuyam Y.A. (2014) Low salinity water flooding: Effect of crude oil composition, in: Paper SPE 169090 Prepared for the SPE IOR Symposium held in Tulsa, USA, 12-16 April. 
Goodwin J. (2009) Colloïds and interfaces with surfactants and polymers, 2nd edn., Wiley, Hoboken, NJ.

Jackson M.D., Vinogradov J., Hamon G., Chamerois M. (2016) Evidence, mechanisms and improved understanding of controlled salinity waterflooding part 1: Sandstones, Fuel 185, 772-793.

Jerauld G.R., Lin C.Y., Webb K.J., Seccombe J.C. (2008) Modeling low-salinity waterflooding, paper SPE 102239, SPE Reserv. Evalu. Eng. 11, 6, 1000-1012.

Kasmaei A.K., Rao D.N. (2014) Is wettability alteration the main cause for enhanced recovery in low-salinity waterflooding, in: Paper SPE 169120 Prepared for the SPE IOR Symposium Held in Tulsa, USA, 12-16 April.

Kwak H.T., Yousef A.A., Al-Saleh S. (2014) New insights on the role of multivalent ions in water-carbonate rock interactions, in: Paper SPE 169112 Prepared for the SPE IOR Symposium Held in Tulsa, USA, 12-16 April.

Lager A., Webb K.J., Black C.J.J., Singleton M., Sorbie K.S. (2008) Low salinity oil recovery - An experimental investigation, Petrophysics 49, 1, 28-35.

Lee S.Y., Webb K.J., Collins I.R., Lager A., Clarke S.M., O'Sullivan M., Routh A.F., Wang X. (2010) Low salinity oil recovery - increasing understanding of the underlying mechanisms, in: Paper SPE 129722 Prepared for the 17th SPE IOR Symposium Held in Tulsa, OK, USA, 24-28 April.

Lenormand R., Eisenzimmer A., Zarcone C. (1993) A novel method for the determination of water/oil capillary pressures of mixed wettability samples, SCA Conference Paper Number 9322.

Mahzari P., Sohrabi M. (2015) Impact of micro-dispersion formation on effectiveness of low salinity waterflooding, in: Paper Tu B09 Presented at the 18th European Symposium on IOR, Dresden, Germany, 14-16 April.

McGuire P.L., Chatham J.R., Paskvan F.K., Sommer D.M., Carini F.H. (2005) Low salinity oil recovery: An exciting new EOR opportunity for Alaska's North Slope, in: Paper SPE 93903 Prepared for Presentation at the Western Regional Meeting held in Irvine, CA, USA, 30 March-1 April.

Mugele F., Siretanu I., Kumar N., Bera B., Wang L., Maestro A., Duits M., van den Ende D., Collins I. (2014) Charge control and wettability alteration at solid-liquid interfaces, in: Paper SPE 169143 Prepared for the SPE IOR Symposium Held in Tulsa, USA, 12-16 April.

Qiao C., Li L., Johns R.T., Xu J. (2014) A mechanistic model for wettability alteration by chemically tuned water flooding in carbonate reservoirs, in: Paper Prepared for the SPE Annual Technical Conf. 8 Exh. Held in Amsterdam, 27-29 October.

Robertson E.P. (2007) Low-salinity waterflooding to improve oil recovery - Historical field evidence, in: Paper SPE 109965 Prepared for the 2007 SPE Annual Technical Conference and Exhibition, Anaheim, California, 11-14 November. doi: 10.2118/109965-MS.

Romanuka J., Hofman J.P., Ligthelm D.J., Suijkerbuijjk B.M.J.M., Marcelis A.H.M., Oedai S., Brussee N.J., Van der Linde H.A., Aksulu H., Austad T. (2012) Low salinity EOR in carbonates, in: Paper SPE 153869 Prepared for the 18th SPE IOR Symposium, Tulsa, USA, 14-18 April.

Sandengen K., Melhuus K., Josang L.O. (2015) Osmosis as Mechanism for Low Salinity EOR, in: Paper We $\mathrm{B0} 3$ Presented at the 18th European Symposium on IOR, Dresden, Germany, 14-16 April.

Seccombe J., Lager A., Jerauld G., Jhaveri B., Buikema T., Bassler S., Denis J., Webb K., Cockin A., Fueg E. (2010) Demonstration of low-salinity EOR at Interwell Scale, Endicott
Field, Alaska, in: Paper SPE 129692 Prepared for the 17th SPE IOR Symposium Held in Tulsa, OK, USA, 24-28 April.

Sharifi M., Shaikh M. (2013) Investigation of optimum salinity of injected water in carbonate reservoirs using wettability measurement and core flooding, in: Paper SPE 165992 Prepared for Presentation at the SPE Reservoir Characterisation and Simulation Conf. and Exh. Held in Abu Dhabi, UAE, 16-18 Sept.

Skauge A. (2013) Low salinity flooding - a critical review, in: Paper A11 Presented at the 17th European Symposium on IOR, 16-18 April 2013.

Skrettingland K., Holt T., Tweheyo M.T., Skjevrak I. (2010) Snorre low salinity water injection - core flooding experiments and single well field pilot, in: Paper SPE 129877 Prepared for the 2010 SPE IOR Symposium, Tulsa, USA, 24-28 April.

Suijkerbuijk B.M.J.M., Hofman J.P., Ligthelm D.J., Romanuka J., Brussee N., van der Linde H.A., Marcelis A.H.M. (2012) Fundamental investigations into wettability and low salinity flooding by parameter isolation, in: Paper SPE 154204 Prepared for the 18th SPE IOR Symposium, Tulsa, USA, 14-18 April.

Tang G., Morrow N. (1999) Influence of brine composition and fines migration on crude oil/brine/rock interactions and oil recovery, JPSE 24, 99-111.

Uetani T., Kaido H., Yonebayashi H. (2019) Investigation of anhydrite dissolution as a potential low salinity waterflooding mechanism in carbonates, in: Paper P07 Presented at the 20th European Symposium on IOR, Pau, 8-11 April.

Van Winden J.F., Suijkerbuijk B.M.J.M., Joekar-Niasar V., Brussee N.J., van der Linde H.A., Marcelis A.H.M., Coorn A.H., Pieterse S.G.J., Ganga K.S., Al-Qarshubi I.S.M. (2013) The critical parameter for low salinity flooding - the relative importance of crude oil, brine and rock, in: Paper A12 Presented at the 17th European Symposium on IOR, St. Petersburg, Russia, 16-18 April.

Vledder P., Fonseca J.C., Wells T., Gonzalez I., Ligthelm D. (2010) Low salinity water flooding: proof of waterflooding alteration on a field wide scale, in: Paper SPE 129564 Prepared for the 17th SPE IOR Symposium, Tulsa, USA, 24-28 April.

Webb K.J., Black C.J.J., Al-Ajeel H. (2004) Low salinity oil recovery - log-inject-log, in: Paper SPE 89379 Prepared for the 14th SPE IOR Symposium, Tulsa, USA, 17-21 April.

Webb K.J., Black C.J.J., Tjetland G. (2005) A laboratory study investigating methods for improving oil recovery in carbonates, in: IPTC 10506, Doha, Qatar.

Yousef A.A., Al-Saleh S., Al-Kaabi A., Al-Jawfi M. (2011) Laboratory investigation of the impact of injection-water salinity and ionic content on oil recovery from carbonate reservoirs, paper SPE 137634, SPE Reserv. Evalu. Eng. 14, 5, $578-593$.

Yousef A.A., Liu J., Blanchard G., Al-Saleh S., Al-Zahrani T., Al-Zahrani R., Al-Tammar H., Al-Mulhim N. (2012) Smart water flooding: Industry's first field test in carbonate reservoirs, in: Paper SPE 159526 Presented at the SPE ATCE, San Antonio, Texas, USA, 8-10 Oct.

Zaheri S.H., Khalili H., Sharifi M. (2020) Experimental investigation of water composition and salinity effect on the oil recovery in carbonate reservoirs, Oil Gas Sci. Technol. - Rev. IFP Energies nouvelles 75, 21. doi: 10.2516/ogst/2020010.

Zahid A., Stenby E.H., Shapiro A.A. (2012) Smart waterflooding (high sal/low sal) in carbonate reservoirs, in: Paper SPE 154508 Presented at the EAGE/SPE Europec Annual Conf. $\&$ Exh. Held in Copenhagen, Denmark, 4-7 June.

Zhang Y., Sarma H. (2012) Improving Waterflood Recovery Efficiency in Carbonate Reservoirs through Salinity Variations 
and Ionic Exchanges : A Promisisng Low-Cost "SmartWaterflood Approach", in: Paper SPE 161631 Presented at the ADIPEC Held in Abu Dhabi, UAE, 11-14 November.

Zhang P., Tweheyo M.T., Austad T. (2007) Wettability Alteration and Improved Oil Recovery by Spontaneous Imbibition of Seawater in Chalk : Impact of the Potential Determining Ions: $\mathrm{Ca}^{2+}, \mathrm{Mg}^{2+}$ and $\mathrm{SO}_{4}^{2-}$, Colloïds Surf. A Physicochem. Eng. Aspects 301, 199-208.

\section{Appendix}

\section{Cationic exchange in clayey rocks}

We consider a clayey rock with a given Cationic Exchange Capacity (CEC), which can be determined from its clay content and composition in different clay minerals (kaolinite, illite, chlorite, montmorillonite, etc.) characterized by their respective CEC values (in equivalent moles per unit volume of solid mineral).

Total salinity (Total Dissolved Salts [TDS]) of the injected brine as well as its composition in monovalent and divalent cations are known and input.

The following variables are defined:

- $S$ as the total equivalent ion mole concentration of cations in the brine.

- $v_{\mathrm{w}+}$ and $v_{\mathrm{w}++}$ as the molar concentrations of monovalent and divalent cations in the brine (moles of cation per liter of solution).

$-\alpha$ as the equivalent ion mole ratio between divalent cations and monovalent cations in solution.

- $v_{r+}$ and $v_{r++}$ as the adsorbed concentrations of monovalent and divalent cations on the rock (moles of cation per liter of solid rock),

- $\beta$ as the equivalent ion mole ratio between adsorbed divalent cations and adsorbed monovalent cations.

One can formulate the following relationships for the cations in solution and the adsorbed cations:

$$
\begin{gathered}
S=v_{\mathrm{w}+}+2 v_{w++} \quad \text { and } \quad \alpha=\frac{2 v_{w++}}{v_{w+}}, \\
\mathrm{CEC}=v_{r+}+2 v_{r++} \quad \text { and } \quad \beta=\frac{2 v_{r++}}{v_{r+}} .
\end{gathered}
$$

We infer:

$$
\begin{aligned}
& v_{w+}=\frac{S}{1+\alpha} \quad \text { and } \quad v_{w++}=\frac{\alpha S}{2(1+\alpha)}, \\
& v_{r+}=\frac{\mathrm{CEC}}{1+\beta} \quad \text { and } \quad v_{r++}=\frac{\beta \mathrm{CEC}}{2(1+\beta)} .
\end{aligned}
$$

Cation exchange constant denoted $\chi$ is formulated as:

$$
\chi=\frac{v_{r++} v_{w+}^{2}}{v_{w++} v_{r+}^{2}} .
$$

Replacing cations concentrations by their expressions versus $\alpha, S, \beta$, and $C E C$, we obtain:

$$
\chi=\frac{\beta(1+\beta) S}{\alpha(1+\alpha) \mathrm{CEC}} .
$$

For a given rock and a brine of given concentration and composition, $C E C, \alpha$, and $S$ are known and the only unknown is the adsorbed cation ratio $\beta$, which is solution of the following equation:

$$
\beta^{2}+\beta-\frac{\alpha(1+\alpha) \chi \mathrm{CEC}}{S}=0 .
$$

The solution of that second-order polynom with $\beta$ unknown is:

$$
\beta=\frac{-1+\sqrt{1+4 \frac{\alpha(1+\alpha) \chi \mathrm{CEC}}{S}}}{2} .
$$

\section{Application}

We consider a seawater with the ionic composition found in Yousef et al. (2011) and given in the Table A1 of this Appendix.

In order to determine the ion mole ratio $\alpha$ between divalent cations and monovalent cations of that brine, divalent cations are lumped into a divalent pseudo-cation of molar mass $\mathrm{M}_{++}$. In the present example, $\mathrm{M}_{++}$is equal to $26,8 \mathrm{~g} /$ mole and $\boldsymbol{\alpha}$ equals 0,259 .

For the purpose of cationic exchange calculation, we consider a clayey sandstone with a CEC equal to 3,1 milli-equivalent per $100 \mathrm{~g}$ of rock, which corresponds for instance to the mineralogical composition given by Bazin and Labrid (1991). On the basis of previous reference, the cationic exchange constant as formulated above is taken equal to 23,4 with solution and adsorbed cation concentrations given in moles per liter of solution and in moles per liter of solid respectively.

We will calculate the evolution of cations distribution between solution and rock surface, when the total cation equivalent mole concentration $S$ is reduced at fixed ionic composition, i.e. at fixed $\beta$ ratio. TDS is then changed in the same ratio as $S$ because the small variation of brine density can be neglected for first-order analysis.

We will also determine the evolution of cations distribution when divalent cations are replaced by monovalent cations ( $\alpha$ ratio is modified) while keeping their total equivalent-mole concentration $S$ (TDS is then changing because of different masses of equivalent ion-moles of monovalent and divalent ions).

These two calculations enable us to determine the respective impacts of dilution and of brine concentration in divalent cations on the amount of adsorbed divalent cations that are assumed to contribute to the oil wettability of the rock.

Calculations are performed:

(a) With a mole dilution ratio ranging from 1 to 0,005 i.e. for $S$ ranging from its original value of 1,017 equivalent ion-mole per liter in the sea water to 0,0051 (TDS reduced from $57000 \mathrm{ppm}$ to $280 \mathrm{ppm}$ ), at fixed $\boldsymbol{\alpha}$ equal to the original sea water value of 0,259 . 
Table A1. Brine ionic composition (Yousef et al., 2011).

\begin{tabular}{lccccccc}
\hline Ions & $\mathrm{Na}^{+}$ & $\mathrm{Ca}^{2+}$ & $\mathrm{Mg}^{2+}$ & $\mathrm{Cl}^{-}$ & $\mathrm{HCO}_{3}^{-}$ & $\mathrm{SO}_{4}^{2-}$ & TDS \\
\hline Mass fraction, ppm & 18300 & 650 & 2110 & 32200 & 120 & 4290 & 57670 \\
\hline
\end{tabular}

Sensitivity of adsorbed divalent \& monovalent cations to brine dilution (at fixed ionic composition of brine $(\alpha=0,259))$

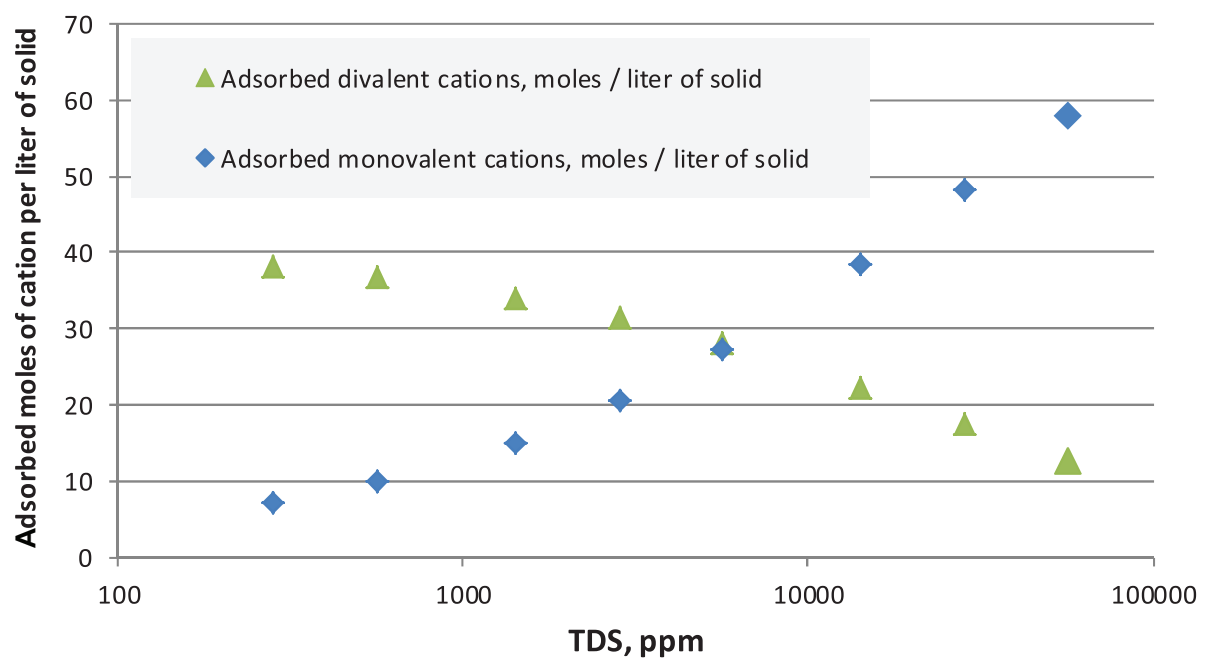

Fig. A1. Sensitivity of cations adsorption to brine concentration.

\section{Sensitivity of adsorbed divalent/monovalent cation ratio $(\beta)$ to brine dilution (with fixed cation ratio $(\alpha=0,259)$ in solution)}

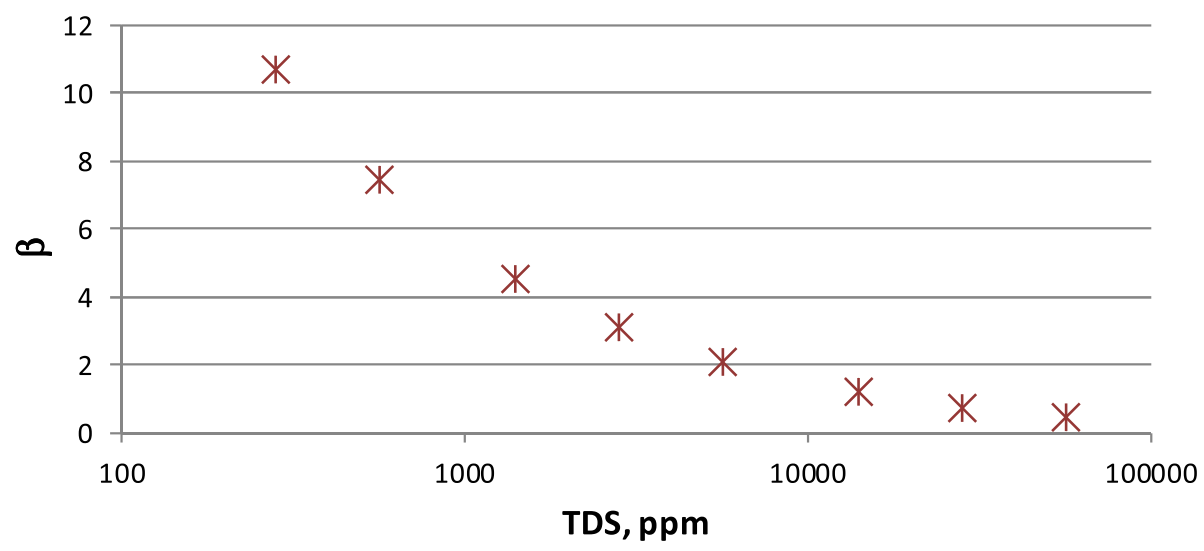

Fig. A2. Illustration of the preferential adsorption of divalent cations when brine is diluted.

(b) With $\alpha$ ranging from 0,259 to 0,001 at fixed amount of equivalent ion-moles of cations $(S)$ equal to the value $1,017 \mathrm{~mole} / \mathrm{L}$ of the original sea water.

Figure A1 shows that more divalent cations and less monovalent cations are adsorbed on the rock when the brine is diluted without changing its ionic composition. A dilution of the initial brine of $1 / 10$ leads to an increase of adsorbed divalent cations to more than twice the initial value at $57000 \mathrm{ppm}$, and to a decrease of adsorbed monovalent cations by a factor close to 2 . That result is also illustrated by Figure A2 showing the increase of $\beta$ when TDS is reduced. TDS is used instead of $S$ in Figures A1 and A2 because both variables are changed proportionally to the mole dilution ratio. So the dilution of brine leads to the preferential retention of divalent cations on the rock surface, because of the higher affinity of divalent cations for the rock and the necessity to satisfy the deficit of positive charges of clay minerals (quantified by the CEC). As per the solution equation for $\beta$, it is noteworthy that the increase of $\beta$ with $S$ (or TDS) decrease occurs for any set of given values for CEC, $\chi$, and $\alpha$. 


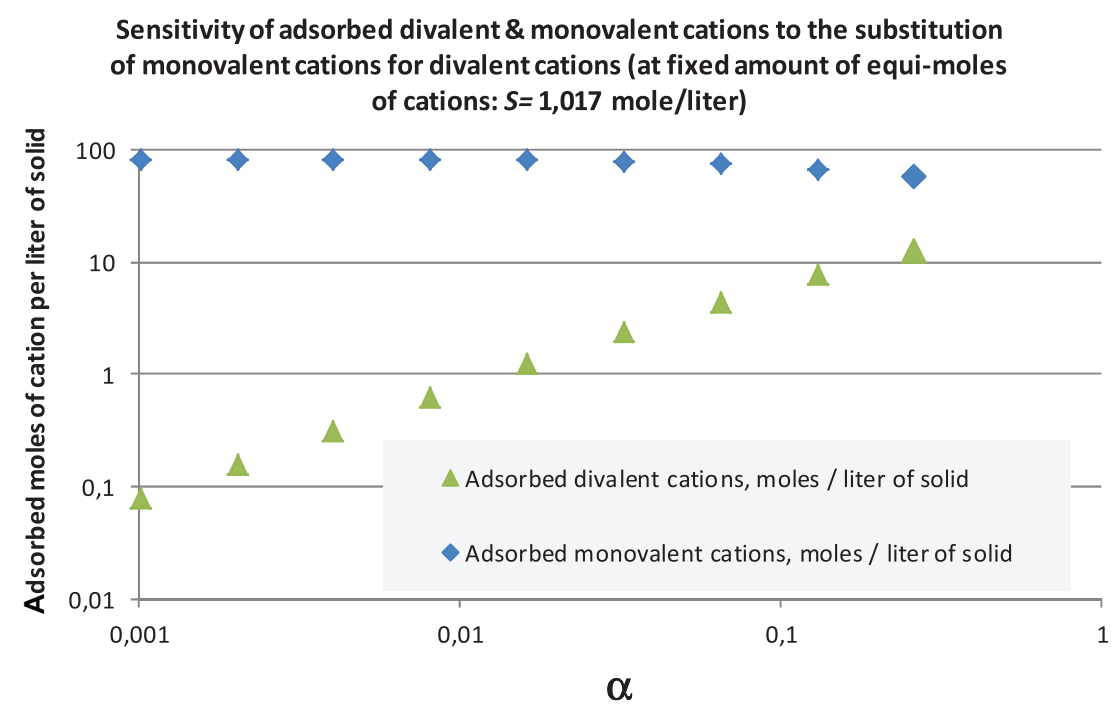

Fig. A3. Sensitivity of cations adsorption to the brine composition characterized by the ratio $\alpha$ between monovalent and divalent cations concentrations.
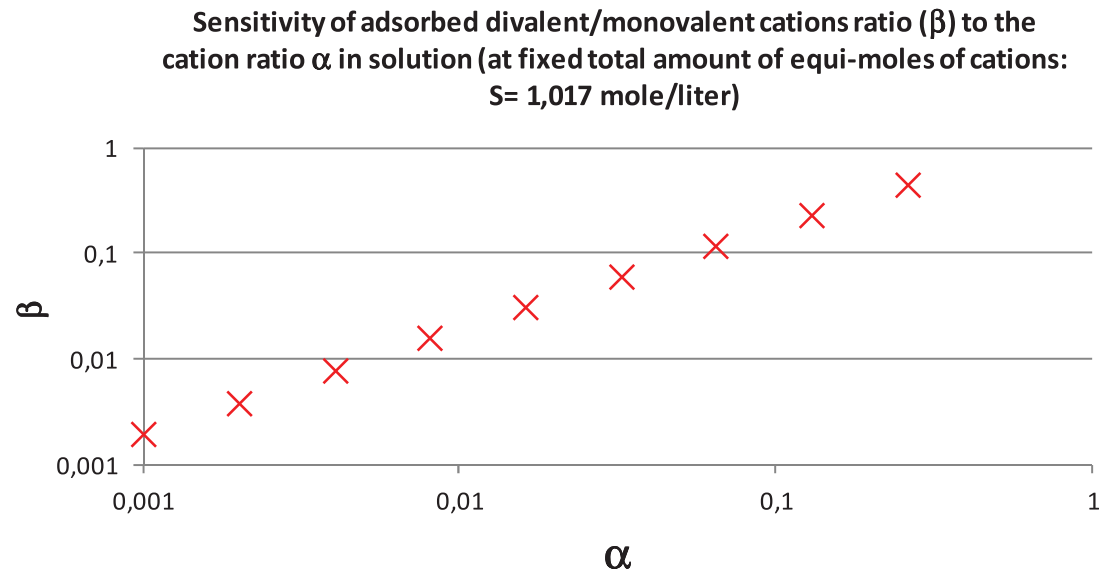

Fig. A4. Illustration of the reduced adsorption of divalent cations when brine composition is modified in favor of monovalent cations.

Figures A3 and A4 illustrate the effect of a replacement of divalent cations by monovalent cations in the brine while keeping its total cation equivalent mole concentration ( $S$ value). Contrary to the brine dilution effect, that substitution leads to a strong reduction of the amount of adsorbed divalent cations that are then replaced by monovalent cations to satisfy the CEC. Figures A3 and A4 show that reducing the divalent-to-monovalent ratio $(\alpha)$ in the brine by a given factor leads to a decrease of adsorbed divalent cations and of $\beta$ ratio by a factor of the same order of magnitude.

To conclude, previous calculations show that for clayey rocks, the positive effects of brine dilution on oil recovery cannot be attributed to a cation exchange mechanism because the adsorption of divalent cations is enhanced by dilution and divalent cations are reputed to favor the retention of polar oil components on the rock. On the contrary, the injection of a brine with a reduced divalent-to-monovalent cation ratio reduces the proportion of adsorbed divalent cations, which is presumably favorable to a higher rock wettability to water and to oil recovery.

Yet, the benefits of brine dilution have been observed in a large number of cases, hence a mechanism other than cation exchange has to be invoked.

In reality, there exists a spatial distribution of interacting ions around a charged solid surface, and ions may play the role of a bridge between some oil components and the rock. As dilution around a charged solid spreads that distribution of interacting ions (under given electrostatic conditions), one may expect an effect on oil-rock interactions and oil trapping. That physical mechanism is analyzed in the body of this paper. It is triggered by brine dilution and also, but to a lesser extent (depending on the original concentration of divalent cations) by the substitution of monovalent cations for divalent cations. 